\title{
Approach to an Affordable and Productive Space Transportation System
}

\author{
Carey M. McCleskey ${ }^{*}$ and Russel E. Rhodes (ret.) ${ }^{\dagger}$ \\ NASA Kennedy Space Center, Florida, 32899 \\ Roger A. Lepsch ${ }^{*}$ \\ NASA Langley Research Center, Hampton, Virginia, 23681-2199 \\ Edward M. Henderson (ret.) $)^{\S}$ \\ NASA Johnson Space Center, Houston, Texas, 77058 \\ And \\ John W. Robinson ${ }^{* *}$ \\ Propellant Supply Technology, Seal Beach, California, 90740
}

\begin{abstract}
This paper describes an approach for creating space transportation architectures that are affordable, productive, and sustainable. The architectural scope includes both flight and ground system elements, and focuses on their compatibility to achieve a technical solution that is operationally productive, and also affordable throughout its life cycle. Previous papers by the authors and other members of the Space Propulsion Synergy Team (SPST) focused on space flight system engineering methods, along with operationally efficient propulsion system concepts and technologies. This paper follows up previous work by using a structured process to derive examples of conceptual architectures that integrate a number of advanced concepts and technologies. The examples are not intended to provide a nearterm alternative architecture to displace current near-term design and development activity. Rather, the examples demonstrate an approach that promotes early investments in advanced system concept studies and trades (flight and ground), as well as in advanced technologies with the goal of enabling highly affordable, productive flight and ground space transportation systems.
\end{abstract}

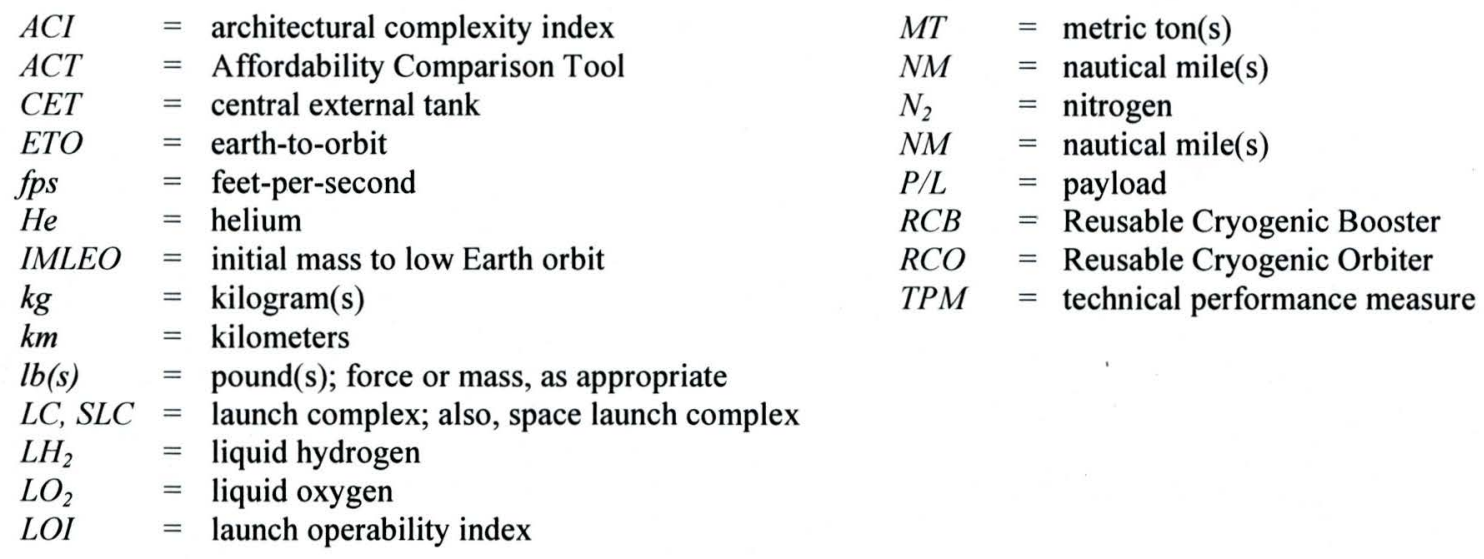

\footnotetext{
${ }^{*}$ Aerospace Technologist, Engineering Directorate, NASA Kennedy Space Center, mail code NE-D3; AIAA Senior Member.

${ }^{\dagger}$ Aerospace Technologist, NASA Kennedy Space Center, retired, and AIAA Senior Member.

$\ddagger$ Aerospace Technologist, Systems Analysis and Concepts Directorate, NASA Langley Research Center, Mail Stop 451.

${ }^{\S}$ NASA/JSC Space Shuttle Program, Advanced Studies, retired, and AIAA Associate Fellow.

*** Propellant Supply Technology; chairman, Space Propulsion Synergy Team, and AIAA Associate Fellow.
} 


\section{Introduction}

With better than 20 years' experience, the von Braun team preached and practiced that rocket and launch pad must be mated on the drawing board, if they were to be compatible at the launching. The new rocket went hand in hand with its launching facility.

Moonport (NASA SP-4204)

C. D. Benson \& W. B. Faherty

1978

$\mathrm{T}$

HIS PAPER presents a structured conceptual design approach that derives an overall architecture focused on affordable, productive, and sustainable space transportation. ${ }^{*}$ The approach covers both vehicle and ground system functions, and incorporates elements of engineering design previously described in technical papers presented by the Space Propulsion Synergy Team (SPST). ${ }^{1,2}$

Examples from the process are for Earth-to-orbit (ETO) transportation-not for near-term commitment, but as a means for identifying mid-term, order-of-magnitude improvements for investment in next generation applications (next five to ten years). The same general process can also be applied for farther term/two-orders-of-magnitude capability improvements for investments in higher risk/higher payoff propulsion technology research and development. The example architectural concept is aimed at simultaneously: (1) lowering the cost-per-pound to orbit; and, (2) significantly increasing the overall payload throughput from any previously achieved by an ETO architecture.

Space architects frequently make trade-offs on conceptual vehicle designs that optimize flight and mission performance (often aimed at minimum vehicle weight or maximum payload performance per flight), and then "down select" one or two for further design commitment. It is generally after vehicle selection that a comprehensive set of flight and ground subsystem functions are addressed (or decomposed) for further architectural definition. It is also after the vehicle is selected that concepts for recurring production and operations are fully understood in terms of recurring cost burdens and cycle time. As a result, the life cycle affordability and productivity are discovered after commitment to the architecture, and often are not pursued as required objectives to meet during design effort. The problem is that if the concept is assessed to be unaffordable to own and operate, at any point its life cycle, then the concept is unsustainable. To avoid this outcome, it is important to follow a structured procedure focused on setting and achieving the measurable architectural goals and objectives outlined in this paper.

Affordable, productive ETO architectures are the focus of the SPST approach. This approach first separates the "what" from the "how", avoiding premature design commitment to a vehicle architecture until the flight and ground systems are made compatible with one another-and most importantly, with expected life cycle affordability and productivity outcomes. The solution is to systematically derive a list of as many key features as possible that enables architectural design approaches that satisfy the overall needs, goals, and objectives. Then, the procedure puts those features together in a conceptual vehicle and ground element architectural design.

Following a short background section introducing key terms and definitions, subsequent sections of the paper will cover the specifics of the procedure outlined in Figure 1.

\footnotetext{
1. Understand the space markets and define viable space business needs for the implementation timeframe

2. Identify space transportation affordability and productivity improvement goals and quantify the objectives

3. Formulate architectural design criteria and understand architectural functions across the life cycle

4. Identify potential building block solutions (the how's) - a systems improvement approach from the inside out

5. Build and size vehicle and compatible ground system conceptual design from potential building block solutions

6. Estimate the magnitude of improvement in the architectural life cycle characteristics

7. Summarize, communicate results, and continually improve to achieve
}

Figure 1-Approach for Creating an Affordable, Productive, and Sustainable Architectural Concept

\footnotetext{
* While this paper covers the general approach and the flight half of the architectural concept, a companion paper was prepared by Garcia, et al, for the $\mathbf{4 8}^{\text {th }}$ Joint Propulsion Conference, titled "A Systems Approach to Developing an Affordable Space Ground Transportation Architecture using a Commonality Approach.”
} 


\section{Key Concepts, Definitions and Background}

\section{A. Key Concepts and Definitions}

1. AFFORDABILITY \& SUSTAINABILITY - Affordability is a characteristic of a capability that is a measure of what you have (e.g., time, money) vs. your ability to bear the cost. If at any time during the life cycle, affordability is exceeded, the system cannot be sustained. ${ }^{3}$ Sustainability is the ability to remain affordable and productive throughout the life cycle of the architecture.

a. Affordability does not in itself measure value

b. $\quad$ Value $\equiv$ operational benefits/non-recurring investments

c. Improving affordability contributes to a higher value

2. LIFE CYCLE-includes the timeframe required to acquire and operate the architecture.

a. Phases include the Non-recurring and Acquisition phase and the Recurring Operations Phase

b. Life Cycle functions include:

i. $\quad$ Non-Recurring System Design, Development, Testing, \& Evaluation (DDT\&E)

ii. Recurring Space Flight Element Production and Final Assembly

iii. Recurring Space Transportation Ground and Flight Operation

iv. Recurring Space Transportation Business Integration

v. Space Transportation Flight System Performance

vi. $\quad$ Space Transportation Ground System Performance (flight rate/throughput

vii. $\quad$ Non-recurring System Retirement, Transition and Disposition

3. PRODUCTIVENESS \& PRODUCTIVITY - Productiveness is the effectiveness what the system produces on a regular basis. For space transportation it may be measured in space flights per unit time, or in terms of throughput (annual payload mass delivered, annual seats provided, etc.). Productivity is the efficiency with which a given level of production is obtained. It is measured by the production level output (productiveness) relative to the input (an organization's labor level, for example).

4. SPACE BUSINESS ENTERPRISE \& ARCHITECTURAL CONTEXT - is the economic context within which system architectures are intended to operate and grow. Enterprises may be commercial, civil, or military in nature; as in a commercial space enterprise, a civil government space 'program' (e.g., the ISS Program), or a military 'program'. Space enterprises are intended to operate and grow in the space environment. Space transportation architectures serve the needs of the space enterprise markets and can be conceptualized as the intersection of several perspectives in meeting those need (see Figure 2). ${ }^{4}$

5. MARKET - is one of a variety of systems, institutions, procedures, social relationships, and infrastructures where parties engage in exchange. For example, the space transportation marketplace can be viewed as a series of transactions, as conceptualized in Figure 3. A specific space markets is composed of a number of mission, and thus transportation, needs.

- $\quad$ Design Reference Market: made up of reference missions (DRMs) and is a starting point for an architectural design effort aimed at satisfying the needs of a space market. Concept trades and preliminary system definitions focus on the meeting a variety of specified space missions.

6. MISSION - is for space flight, a specific need that can be defined by its departure-destination nature, its type of payload, and/or the nature of work performed by the transportation system. Space transportation missions meet specific space market and mission needs; as in a 'Mars mission', an 'ISS mission", a 'cargo mission', an 'assembly mission', a 'retrieval mission', or a 'crewed mission'.

- Design Reference Mission (DRM): A specific space flight profile that is a starting point for an architectural design effort focused solely on that mission. Concept trades and preliminary system definitions focus on the meeting the goals and objectives of the specified mission.

7. $\underline{N E E D}$ - in terms of space flight, is something that is identified to be essential, necessary, or very important to the sustainment of the space enterprise, market, or mission. For this paper the business enterprise needs are the highest level of requirements for the space transportation architecture.

American Institute of Aeronautics and Astronautics 080112 
8. GOAL-is a desired result that system architecture envisions, plans, and commits to achieve by attaining specific and consistent measurable objectives.

9. OBJECTIVE-is a design-to target for fielding operational system architecture. The units and values of all the objectives are mathematically consistent with one another in achieving a larger set of goals.

10. SYSTEM COMPATIBILITY - the orderly, efficient integration and operation between two or more systems with no modification or conversion required. ${ }^{5}$ For example, is the flight system half of the architecture 'compatible' with the ground infrastructure? Or, is the design and development affordability of the architecture 'compatible' with its operational affordability?

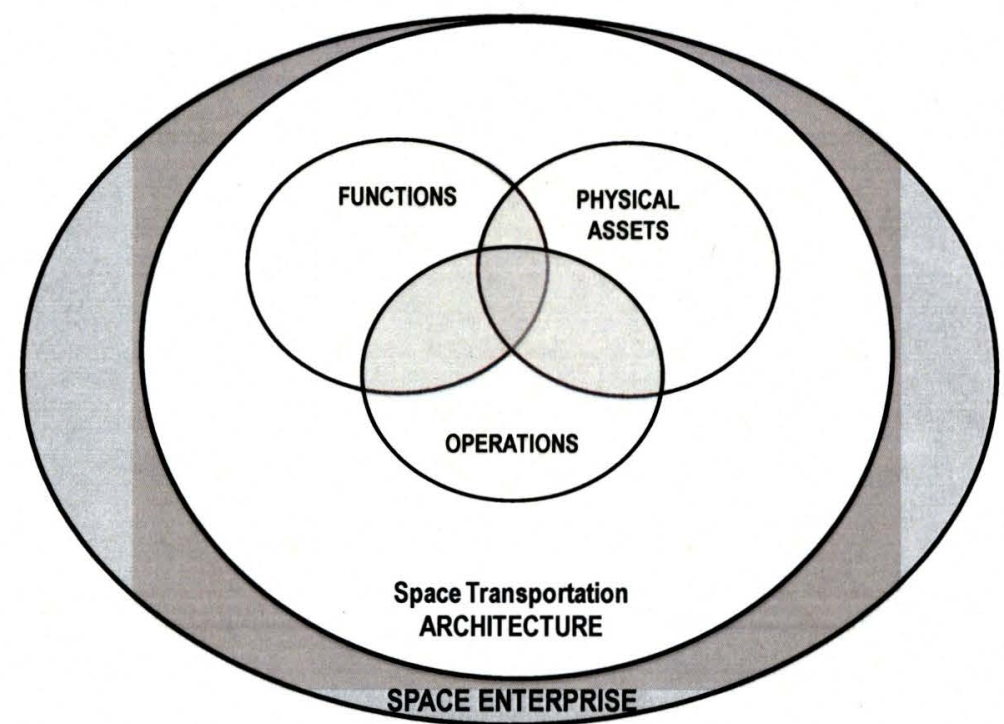

Figure 2-Business context diagram for affordable, productive space transportation architectures

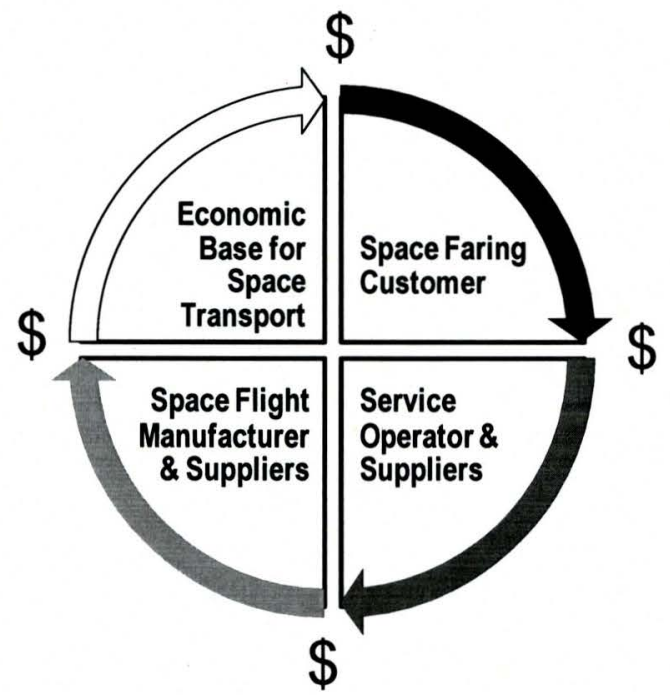

Figure 3-Cycle of transactions fueling future expansion and need for improvements in space transportation

American Institute of Aeronautics and Astronautics 080112 


\section{B. Background}

\section{Methods of Meeting Needs: Missions vs. Markets}

Design reference missions (DRMs) define the needs for space exploration architectures, which drives the physical context of a space transportation system. Because they are focused on meeting the needs of a specific mission, they have tended to be optimized around flight performance parameters. A human exploration mission beyond Earth orbit may define an initial mass to low Earth orbit (IMLEO) as the key performance parameter that discriminates between architectural proposals. In this example, a vehicle concept that maximizes the mass lifted to LEO each flight (i.e., a heavy lift launch vehicle) would best meet the mission requirement.

However, commercial space enterprises are interested in profit. Therefore, to enable expansion of current space markets, and open new ones, the needs of commercial development of space must also take into account the affordability and productivity of the architecture. Missions are accomplished and generally have a defined end; markets need to be sustained. If examining the specific exploration DRM within a larger space market development context, a subtle change in performance emphasis occurs - a transportation system infrastructure is needed that is productive enough to sustain current enterprises and grow new enterprises in new destinations. It must also be efficient enough to provide transportation services at low cost to all the existing and emerging enterprises.

In other words, architectures that simultaneously improve both payload throughput (tons/year) and cost-per-ton (\$/ton) would best meet the market requirement. The examples in this paper demonstrate our approach that strives to engineer simpler, more dependable flight and ground architectures to achieve higher throughput at lower cost-perton, thus enabling new markets to emerge.

\section{Architectural Design Influences on a System's Inherent Affordability and Productivity}

Innovative concepts and technologies with potential to enable architectures that produce flights at substantially lower per-flight costs have been previously identified by NASA. ${ }^{6}$ Additionally, these same studies point to annualized cost-per-pound as a key indicator for market elasticity. ${ }^{7,8}$ Order-of-magnitude reductions from $\$ 22,046 / \mathrm{kg}(\$ 10,000 / \mathrm{lb})$ down to around $\$ 2,205 / \mathrm{kg}(\$ 1,000 / \mathrm{lb})$ are a common result often cited. One of the conclusions of the Future Space Transportation Study in 2000 was "the space launch market is inelastic above a certain launch price point (approximately $\$ 600$ per pound) and elastic for prices below." Key measures contributing to cost-per-pound ${ }^{*}$ are:

(a) Total annual operating cost measured in \$'s/year (i.e., affordable)

(b) Annual payload delivery measured in pounds per year (i.e., productive)

How does the architectural design influence these and other key measure relating across the life cycle? Major drivers are shown on the left side of the diagram in Figure 4. These influence cost and performance elements across the life cycle and comprehensively include the production, operations, and business infrastructure elements of the architecture; which, in turn, determines the outcome on the right side of Figure 4.

Figure 4 also reveals how requirements development can follow the same framework. Beginning with the affordability and productivity desired, the goals for the architectural outcome can be formulated. These goals can then be allocated and mathematically tracked across the architecture and across the non-recurring and recurring life cycle phases. Once measurably defined, the objectives will drive key enabling and enhancing system design features and characteristics. ${ }^{10}$

\footnotetext{
${ }^{*}$ Annualized cost-per-pound is determined from the ratio of annual operating cost to annual payload mass throughput
} 


\section{$\square$ \\ Direction of Design Influence on Affordability/Productivity}

MANORINFLUENCING DESIGN
DRIVERS

Figure 4-Influences on Affordability and Sustainability

\section{Step 1: Needs for Future Space Enterprises, Markets and Missions}

Referring to the first step in Figure 1, the space markets need to be understood and a viable space business needs defined for the implementation timeframe of interest. Activities are identified that could occur in a market place characterized by higher throughput and lower cost-per-ton in the mid- and farther-term; i.e., future needs that more affordable, productive space transportation architectures must satisfy.

\section{Business Enterprise Examples Requiring Low Earth Orbit Transport Services}

Using a business enterprise context provides a foundation for envisioning a marketplace characterized by higher throughput at lower costs. The Organization of Economic Cooperation and Development (OECD) estimated that the space economy represented over $\$ 65 \mathrm{~B}$ and growing in government space budgets alone across the globe in 2010 . Across the space industry segments in the United States OECD estimated that $\$ 150-165 \mathrm{~B}$ in revenues were derived from space-related products and services in $2009 .^{11}$ This represents literally millions and millions of individuals depending and benefiting from healthy growth in the space economy.

Examples of future space business enterprises that can grow from current levels of activity include expansion or establishment of:

a) Telecommunications and climatology services - provided by large-scale, assembled transponder farms that are routinely attached or upgraded, rather than dedicated launches for unique satellite busses dedicated to a small number of transponders

b) Conducting advanced space research, e.g., large-scale astrophysics platforms, artificial gravity assemblies, space solar power arrays, and advanced in-space propulsion experiments 
c) Construction, servicing, repair and expansion of inhabited space facilities, public space travel and, of course, one day space settlements.

d) Construction, servicing, repair and expansion of in-space transportation waypoints, such as propellant depots, and spacecraft assembly facilities for heliocentric transportation systems. These could one day send expeditionary 'flotillas' to near-Earth asteroids, Mars, Venus, the asteroid belt, and the moons of Jupiter and Saturn

e) Space resource exploration and commercial harvesting, such as: space solar power; near-Earth object exploration and mining; construction and operation of lunar-planetary bases

f) Carrying out national security and reconnaissance, and global security and survival (Earth impact protection, for example)

g) Staging of exploration missions beyond earth orbit; i.e., LEO delivery of exploration system elements that are either constructed in earth orbit, e.g., Mars Design Reference Architecture 5.0. ${ }^{12}$

\section{Timeframe of the needs}

Our timeframe for examination is not near-term design implementation. Innovative design and development efforts are underway now to set the stage for lower launch cost, or increases in heavy lift.

\section{Relating space enterprise needs to an architectural vision for space transportation}

We wish to advance our architectural vision to one that comprised of constantly flowing goods and services, on an economically-viable basis, from Earth-based economic elements to and from space. Systems and infrastructure that transport people and cargo by land, sea, and air currently sustain our existence on Earth; and slowly, but ever increasingly, space transportation is becoming an ever-increasing factor in our daily existence not in small part to commercial start-ups. In the not so distant future, it will become as essential as air travel and ocean travel is today.

\section{Example Needs List for Space Enterprise Transportation Needs}

[N-1] Frequent and high volume cargo deliveries

Rationale: Required for enterprises that resupply and/or assemble for revenue-generating opportunities.

[N-2] Frequent and high volume passenger deliveries

Rationale: Required for enterprises needing revenue-generating opportunities from passengers.

[N-3] Safe, comfortable, unburdened launch and landing experience for the passengers

Rationale: Required for enterprises attracting passengers.

[N-4] Dependable arrivals and departures at the space enterprise locations

Rationale: Required for enterprises depending on resupply for sustainment, and occupancy rates for enterprises depending on steady passenger/crew business.

[N-5] Ability to conduct routine assembly, servicing, and repair activities at a variety of destination locations (possesses large-scale in-space element and component handling devices)

Rationale: Required for enterprises depending on servicing and repair, as well as mobile construction capabilities for expansion of their space enterprise, wherever it is located.

[N-6] Ability to conduct space rescue missions anytime, anywhere in earth orbits.

Rationale: To protect the humans and our economic interests - an Earth orbiting "Coast Guard".

[N-7] A means of routine, affordable transportation from one Earth orbit to another Earth orbit

Rationale: Provide low-cost in-space transport from LEO to geo-stationary Earth orbit (GEO), or other useful locations-a space-based orbital transfer service using orbital transfer vehicles (OTVs).

[N-8] Ability to house embedded airlocks for personnel transfer without time and effort involved for entire crew cabin to be evacuated and all personnel in cabin to don and doff pressure suits

Rationale: Required for in-space human activity; particularly for assembly, servicing, or repair operations

[N-9] Clean, effluent-free environment around arriving spacecraft

a) Rationale: Required of space transportation system to avoid space transportation architecture interrupting or degrading the operation due to spacecraft subsystem effluents, corrosive attitude control exhaust, etc.

Figure 5 -Space Enterprise Needs for Affordable and Sustainable Transportation with Rationale

\footnotetext{
${ }^{*}$ These needs apply to both commercial and government enterprises; however, their priorities and timeframes may be different.
} 


\section{Step 2: Goals and Objectives for More Affordable and Productive Space Transportation}

\section{A. Establishing Mid- And Far-Term Space Transportation Architecture Goals \\ 1. Establishing mid- and far-term affordability goals}

Referring once again to Figure 1, the next step is to identify space transportation affordability and productivity improvement goals and quantify the objectives. Our examples quantify the increase in payload affordability in terms of a decrease in cost-per-pound. Currently, the cost to the payload customer is typically in the $\$ 22,000 / \mathrm{kg}$ $(\sim \$ 10,000 / \mathrm{lb})$ range for launch capability to a standard low Earth orbit at $185 \mathrm{~km}(100$ miles, nautical $)$ circular, to a due east azimuth from $28.5 \mathrm{deg}$. latitude. Lower costs for about half that $\$ 11,000 / \mathrm{kg}(\sim \$ 5,000 / \mathrm{lb})$ can be found published for a recent NASA Delta II purchase for its Discovery program, and about a quarter of that, or $\$ 4,200 / \mathrm{kg}$ $(\sim 1,900 / \mathrm{lb})$ for a contemporary commercial provider's web-posted price. ${ }^{13,14}$ Therefore, a goal of roughly half this amount, say $\$ 1,000 / \mathrm{lb}$ will do as an architectural affordability goal for our example - in the farther term, perhaps $\$ 100 / \mathrm{lb}$

\section{Establishing mid-and far-term throughput (productiveness) goals}

Our examples must similarly comply with a goal for productiveness to fully satisfy the ambitious needs of future markets. The highest annual yields of payload delivered have been from the Soyuz/Molniya system in the 1980s and the Space Shuttle system in the 1990s. ${ }^{15,16}$ More recently, the Ariane V system (single string ELA-3 infrastructure at Kourou) achieved a peak flight rate of seven (7) flights during 2009, delivering about 45 MT-primarily to GTO destinations. ${ }^{17}$ Many of these architectures operate out of multiple sets of pads, launch facilities, and even fleets of reusable orbiters. The inherent capability of the architectural design can be captured by looking at its performance per "string" of assets; i.e., per single set of facilities, or single vehicle in a fleet. Comparing these three existing systems on a per-system-string basis works out to:

$$
\begin{aligned}
& \text { Examples of demonstrated high throughput delivery systems normalized to single-string performance } \\
& \qquad \begin{aligned}
1980 \text { Soyuz } & \approx 330 \mathrm{MT} / \text { year and } 13 \text { seats/year } \div 4 \text { launch complexes } \\
& \approx 82.5 \mathrm{MT} / \text { year and } 3.3 \text { seats/year per launch complex } \\
& \approx 110 \mathrm{MT} / \text { year and } 58 \text { seats/year } \div 3 \text { Orbiters or } 1 \text { launch complex } \\
& \approx 110 \mathrm{MT} / \text { year and } 58 \text { seats/year per launch complex } \\
& \approx 37 \mathrm{MT} / \text { year and } 19.3 \text { seats/year per Orbiter } \\
& \approx 45 \mathrm{MT} / \text { year (1 launch complex/pad; ELA-3); almost all to GTO } \\
& \approx 90 \mathrm{MT} / \text { year for LEO-equivalent delivery }
\end{aligned}
\end{aligned}
$$

On the near-term horizon are the commercial expendable Falcon Heavy (Falcon-H) of about 53 MT to LEO delivery capability per flight, and the expendable NASA Space Launch System (SLS) of tons. Translating these expected capabilities to actual launch delivery rates and manifested load factors, as above for existing systems, is beyond the scope and purpose of this work. However, ten Falcon-H vehicles are planned to be launched annually from two launch complexes (LC-39/KSC and SLC-4E/VAFB), and 2-3 SLS flights/yr planned by NASA. ${ }^{19,20}$

\section{Near-term high throughput delivery systems}

$$
\begin{array}{ll}
>2014 \text { Falcon-H } & \approx 530 \mathrm{MT} / \text { year } \div 2 \text { launch complexes } \\
& \approx 265 \mathrm{MT} / \text { year per launch complex } \\
>2020 \mathrm{SLS} & \approx 210 \mathrm{MT} / \text { year per string }(105 \mathrm{MT} @ 2 \text { flights/year })^{21}
\end{array}
$$

A throughput goal in excess of 500MT/year per string of assets would not be unreasonable for the mid-term in conjunction with an affordability goal that attracted space business enterprises. For farther-term architectural goals, a level of productiveness that is: (1) twice the mid-term, with, (2) an order-of-magnitude reduction in per-mass costs would not be unreasonable. High traffic/heavy-lift transportation services could be supporting creation and operation of large space facilities, or, human lunar-planetary missions and flotilla-style expeditions. Since the examples address the mid- and farther-term timeframes, the authors placed greater emphasis on operational effectiveness (in terms of enabling affordable, productive architectures) and less on up-front acquisition. 
Figure 6 summarizes the architectural goals, stated for our example in terms of affordability and productivity targets, for both mid- and farther-term investments are:

\begin{tabular}{|c|c|c|}
\hline \multicolumn{3}{|c|}{ Example Concept Architectural Goals } \\
\hline $\begin{array}{l}{[\mathrm{G}-1 \mathrm{~A}]} \\
{[\mathrm{G}-1 \mathrm{~B}]}\end{array}$ & $\begin{array}{l}\text { Improved Affordability } \mathrm{f} \\
\text { Mid-term improvement } \\
\text { Farther-term improvement }\end{array}$ & $\begin{array}{l}\text { or Expansion and Growth of the Payload Customer Base } \\
<\$ 2,200 / \mathbf{k g}(\$ 1,000 / \mathbf{l b}) \\
<\$ 220 / \mathbf{k g}(\$ 100 / \mathbf{l b})\end{array}$ \\
\hline $\begin{array}{l}\text { Improve } \\
{[\mathrm{G}-2 \mathrm{~A}]} \\
{[\mathrm{G}-2 \mathrm{~B}]}\end{array}$ & $\begin{array}{l}\text { Productiveness for the Systen } \\
\text { Mid-term improvement } \\
\text { Farther-term improvement }\end{array}$ & 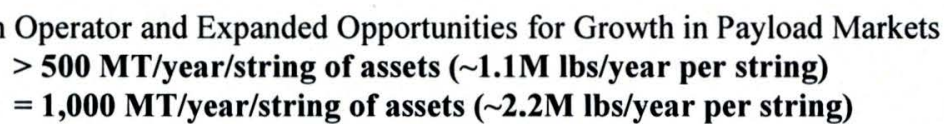 \\
\hline
\end{tabular}

Figure 6-Example Architectural Goals

\section{B. Identify the Objectives That Address the Architectural Goals}

Referring again to Figure 4, specific life cycle affordability and productivity objectives can be determined and traced to the affordability and productivity goals in a mathematically consistent manner.

1. Determine Annual Recurring Production and Operations Cost (System Operating Cost) Objective

In Figure 4 the annual recurring production and operations cost influences such affordability metrics as cost-perpound. By dividing the throughput goals into the affordability goals, an annual recurring production and operations cost objective can be attained. In our mid-term example:

\section{Example Concept System Operating Cost Objective}

$$
\begin{aligned}
\text { Total Annual Recurring Production/Ops Cost } & =\$ 2,200 / \mathrm{kg}(\$ 1,000 / \mathrm{lb}) \times 500 \mathrm{MT} / \text { year }(1.1 \mathrm{Mlb} / \text { year }) \\
& =\$ 2,200 / \mathrm{kg} \times 500,000 \mathrm{~kg} / \mathrm{year} \\
& \sim \$ 1.1 \mathrm{~B} / \text { Year }
\end{aligned}
$$

[0-1A] Recurring Production \& Ops Cost $=\$ 1.1 \mathrm{~B} /$ Year

Figure 7-Example Recurring Production and Operations Cost Objective

2. Balancing of Vehicle Payload Capacity with Flight Rate Capability

Referring back to the influence diagram of Figure 4, architectural objectives need to be derived for the ground operations performance and vehicle payload capacity blocks. The specific metrics involved are:

a) Inherent flight rate capability, measured in flights-per-year-per-string of vehicle or facility assets

b) Vehicle payload capacity, measured in mass-per-flight

The two combined, define the inherent throughput capability of a space transportation system concept (vehicle architecture and ground architecture together). An example relationship between the flight rate, the throughput requirement, the resulting payload size, and cost-per-flight is shown in Figure 8.

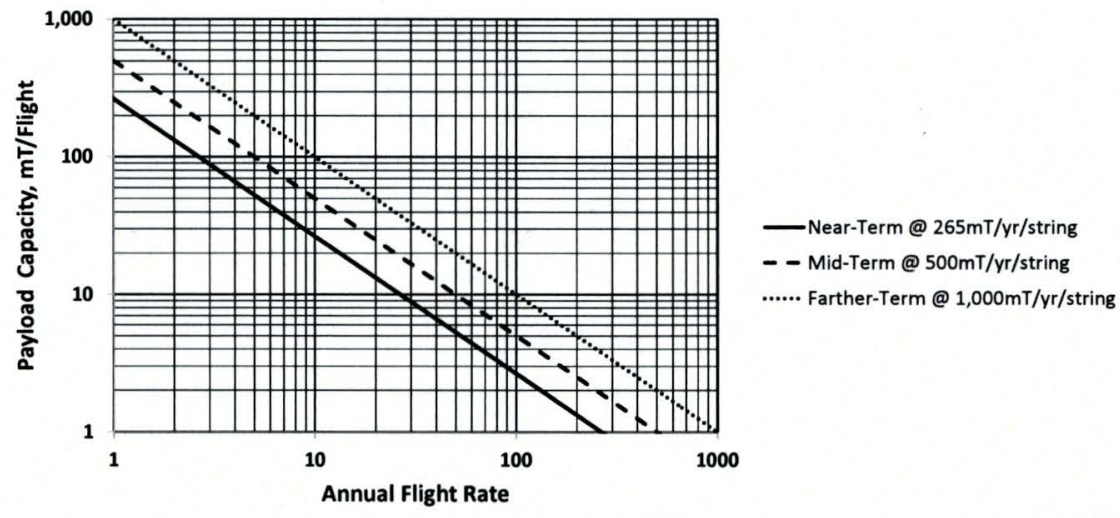

Figure 8-Payload throughput capacity vs. flight rate capability

9

American Institute of Aeronautics and Astronautics 080112 
From a conceptual vehicle performance standpoint, a number of potential missions/architecture concepts that satisfy the ETO business case scenarios are summarized in Table 1, and the Mission 1 capability (highlighted in boldface font in the table) will be the one used for the example architecture. A summary of the needs, goals, and objectives in the examples of this paper is provided in Figure 9.

Table 1-Example of ETO mission objectives for Mid-term improvements in operational usefulness

\begin{tabular}{|l|l|l|}
\hline Mission 1 & $\begin{array}{l}\text { ETO Freighter with } \\
\text { both up/down-mass } \\
\text { capability (Examples) }\end{array}$ & $\begin{array}{l}\text { Payload up-capacity of 25 MT and 10-15 MT down-mass (increase from } \\
\text { Shuttle) to } \mathbf{1 0 0} \mathbf{~ n m ~ L E O ~ d u e ~ e a s t ~ o r b i t , ~ 2 8 . 5 ~ d e g . ~ i n c l i n a t i o n , ~ a n d ~} \\
\text { return-order-of-magnitude reduction in cost/lb for operator. }\end{array}$ \\
\hline Mission 2 & $\begin{array}{l}\text { Propellant/Expedition } \\
\text { Component Delivery }\end{array}$ & $\begin{array}{l}\text { One-way delivery of heavy-lift class payloads (40-90MT / flight) to LEO, } \\
\text { GEO, and heliocentric trajectories, (<\$10,000/lb) }\end{array}$ \\
\hline Mission 3 & $\begin{array}{l}\text { Passenger } \\
\text { SpaceLiner/Orbiter }\end{array}$ & $\begin{array}{l}\text { Large-volume passenger hold (at least } 25 \text { passengers) to } 100 \text { nm due east } \\
\text { orbit 28.5 deg inclination-per-seat costs less than } \$ 2 M \text { (order magnitude } \\
\text { decrease from recent private Soyuz seat prices) }\end{array}$ \\
\hline Mission 4 & Orbital Utility Vehicle & $\begin{array}{l}\text { With a sizable work bay and cargo hold, but also contains an airlock and } \\
\text { crew cabin that can hold at least six (6) to twelve (12) assembly and repair } \\
\text { crew (two shifts of } 3 \text { to 6 crew, or three shifts of } 2 \text { to } 4 \text { crew). Also, 100 nm } \\
\text { due east with 28.5 deg. inclination }\end{array}$ \\
\hline
\end{tabular}

NEEDS OF FUTURE MARKETS/MISSIONS (see Figure 5):

[N-1] Frequent and high volume cargo deliveries

$[\mathrm{N}-2]$ Frequent and high volume passenger deliveries

[N-3] Safe, comfortable launch and landing experience, and unburdened ground experience for the passengers

$[\mathrm{N}-4]$ Dependable arrivals and departures at the space enterprise locations

[N-5] Ability to conduct routine assembly, servicing, and repair activities at a variety of destination locations (possesses large-scale in-space element and component handling devices)

[N-6] Ability to conduct space rescue missions anytime, anywhere in low earth orbit

[N-7] A means of routine, affordable transportation from one Earth orbit to another Earth orbit

[N-8] Ability to house embedded airlocks for personnel transfer without time and effort involved for entire crew cabin to be evacuated and all personnel in cabin to don and doff pressure suits

[N-9] Clean, effluent-free environment around arriving spacecraft

GOALS OF THE ARCHITECTURE (see Figure 6):

Mid-Term Operational Affordability improvement (for LEO $100 \mathrm{NM}, 28.5^{\circ}$ due east inclination)

[G-1A] Cost per unit payload mass \& seat $\quad=\$ 2,200 / \mathrm{kg}(\$ 1,000 / \mathrm{lb}) \& \$ 2.0 \mathrm{M} / \mathrm{seat}$

Mid-Term Productiveness improvement

[G-2A] Payload Throughput Capability

[G-3A] Passenger Throughput Capability

$=500 \mathrm{MT} /$ year/string $(\sim 1.1 \mathrm{M} \mathrm{lbs} . /$ year per string $)$

$=600$ seats/year/string $(\sim 10 \mathrm{x}$ Shuttle system peak $)$

Farther-Term Operational Affordability improvement:

[G-1B] Cost per unit payload mass \& seat

Farther-Term Productiveness improvement:

[G-2B] Payload Throughput Capability

$\sim \$ 220 / \mathrm{kg}(\$ 100 / \mathrm{lb}) \& \$ 100 \mathrm{~K} / \mathrm{seat}$

[G-3B] Passenger Throughput Capability

$\sim 1,000 \mathrm{MT} /$ year ( 2.2M lbs. per year)

$\sim 2,000$ seats/year/string (100x Shuttle system peak)

OBJECTIVES FOR SYSTEM DESIGN: (refer to Figure 7 and section IV.B of this paper):

Mid-Term ( $>2 x$ near-term capability in next ten years; no more than Shuttle flight capacity)

[O-1A] Recurring Production/Ops Cost $\quad<\$ 1.1 \mathrm{~B} /$ year (fixed + one string of assets)

[O-2A] Operational Performance

[O-3A] Vehicle Performance (cargo)

[O-4A] Vehicle Performance (seats)

[O-5A] Design Life/Availability

$>20 \mathrm{flts} /$ year/string (7-day flts +25 -day depot flow)

$\sim 25 \mathrm{MT} /$ flight

$\sim 30$ seats/flight

$\sim 1,000$ flights/ $\mathrm{A}=0.98$ launch-to-launch

Farther-Term (Order-of-magnitude increase from Mid-Term capability in next twenty years)

[O-1B] Recurring Production/Ops Cost $\quad \sim \$ 220 \mathrm{M} /$ Year (Fixed +1 string of veh. \& gnd. assets)

[O-2B] Operational Performance

[O-3B] Vehicle Performance (cargo)

[O-4B] Vehicle Performance (seats)

$\sim 40$ flights/year/string

$\sim 25 \mathrm{MT} /$ flight

$\sim 50$ seats/flight

[O-5B] Design Life/Availability

$\sim 10,000$ flights/A=0.99 launch-to-launch

Figure 9-Summary of Space Transportation Needs, Goals, and Objectives for the Example Concept

American Institute of Aeronautics and Astronautics 080112 


\section{Step 3: Formulate Design Criteria and Understand Architectural Functions Across the Life Cycle}

\section{A. Identify and Prioritize the Architectural Design Criteria}

In the third step of the approach defined in Figure 1, design criteria are formulated for the architectural functions. To facilitate this, the authors drew on several sources. First, it drew upon the SPST's previous work in deriving generic design criteria and eighteen (18) primary technical performance measures (TPMs). Secondly, it drew from an analysis and first-hand experience in Space Shuttle operations and infrastructure.

To quantify and compare proposed architectures, rather than subjectively rank them, Figure 4 was created from the knowledge and experience gained in developing an Affordability Comparison Tool (ACT) prototype at the Kennedy Space Center. The examples in this paper are derived from architectural features that best address these three sources of criteria - all of which are focused on life cycle affordability and sustainability.

1. Eighteen Prioritized SPST Design Criteria for Improving Life Cycle Affordability and Productivity

The Space Propulsion Synergy Team (SPST) has developed, over a number of years and a number of separate tasks, a series of technical performance metrics (TPMs) that would help assure sustainable, operational space transportation system architectures. ${ }^{22}$ The factors to be minimized (in order of importance) are:

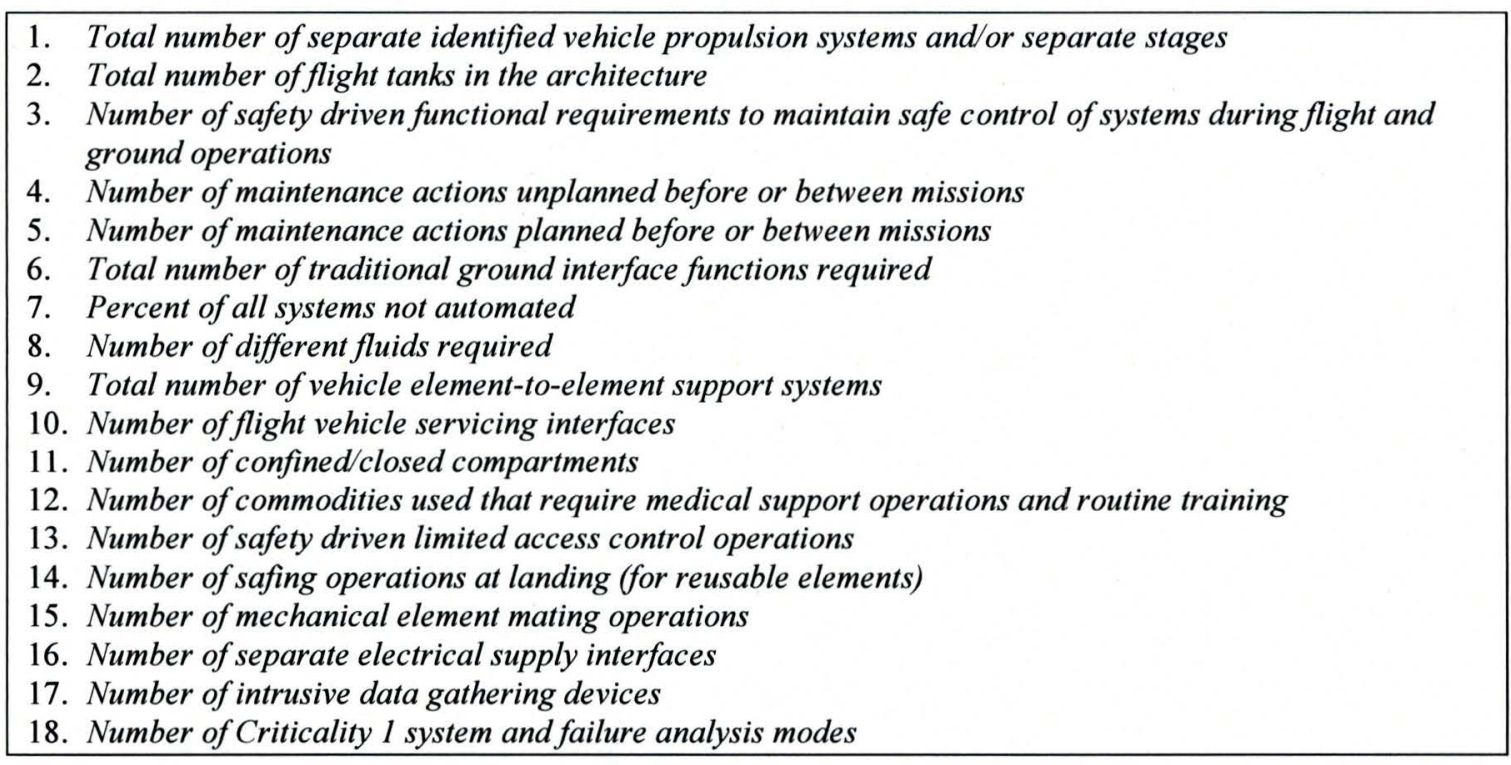

Figure 10-Prioritized Design Criteria for Improvement

\section{Understand Shortfalls in Shuttle Operability, Supportability, and Dependability}

In 2002 NASA KSC engineers undertook a comprehensive analysis of Space Shuttle budget and actual scheduled work (both planned and actual) to characterize where the work concentrations existed, and arrive at a consensus on design choices that cause operational problems (i.e., design root causes). ${ }^{23}$ The source data covered one year's-worth of Shuttle ground operations that resulted in launches during calendar year 1997. After documenting numerous design root causes associated, KSC engineers analyzed common themes and recurring areas of ground operations work associated with the major generic operations functions. These are described in Attachment A in decreasing order of direct work volume.

3. Choose a means of assessing conceptual architectures for affordability and productivity

This step requires a method of consistently assessing the proposed architectural design concepts. It requires methods of examining concepts for insight into overall operational complexity, resulting infrastructure burdens infrastructure. Fortunately, there is groundwork in this area from which the authors can draw:

a) Launch Operability Index (LOI) and ground systems Architectural Complexity Index (ACI)

These indexes assess both the flight system architecture and the ground system architecture around common interface functions to determine (1) functional compatibility, and (2) design complexity as it affects operational affordability and productivity. The Launch Operability Index (LOI) was conceived and 
documented in the Operationally Efficient Propulsion Systems Study (OEPSS) in the 1992 timeframe. ${ }^{24}$ The ground systems Architectural Complexity Index (ACI) is discussed in the sister paper to this paper titled, "A System Approach to Developing a Common Architecture for the 21st Century," by Mr. J. L. Garcia, et al, of NASA Kennedy Space Center.

b) ACT Prototype

NASA Kennedy Space Center is developing a conceptual design trade tool capable of architectural assessments based on algorithms that incorporate the concept of affordability in Figure 4. Known as the Affordability Comparison Tool (ACT), a prototype of this tool generated the example cases run in this paper. The tool not only assesses the operability of a vehicle design, but also its compatibility with the ground architecture by quantitatively measuring system or architectural complexity. The prototype version is anchored primarily on the quantifiable life cycle cost data available from the Space Shuttle Program. ${ }^{25,26,27}$

\section{B. Identify Functional Items Required to Achieve Space Transportation Objectives}

The generic Functional System Breakdown Structure (F-SBS) provides a universal hierarchy of space transportation flight and ground system functions that include ground and space operations, as well as supporting infrastructure. ${ }^{28}$ Since this paper specifically addresses the Earth-to-Orbit (ETO) transportation segment of the space architecture, a top-level set of categories applicable to ETO architectures derived from the full F-SBS is in Attachment B.

\section{Step 4: Identify Potential Building Block Solutions-a Systems Improvement Approach}

The next step identifies specific design methods for implementing the functions; i.e., identify key "building blocks" that show potential for improving the operability, supportability, dependability, and responsiveness of key aspects of the architecture.

\section{A. Architectural Approach}

For the examples the approach will be to define key vehicle and ground element interfacing improvement needs and account for complexity and scale. The concept of system compatibility across key functional interfaces, while maintaining a system solution that is affordable and productive is important (Figure 11).

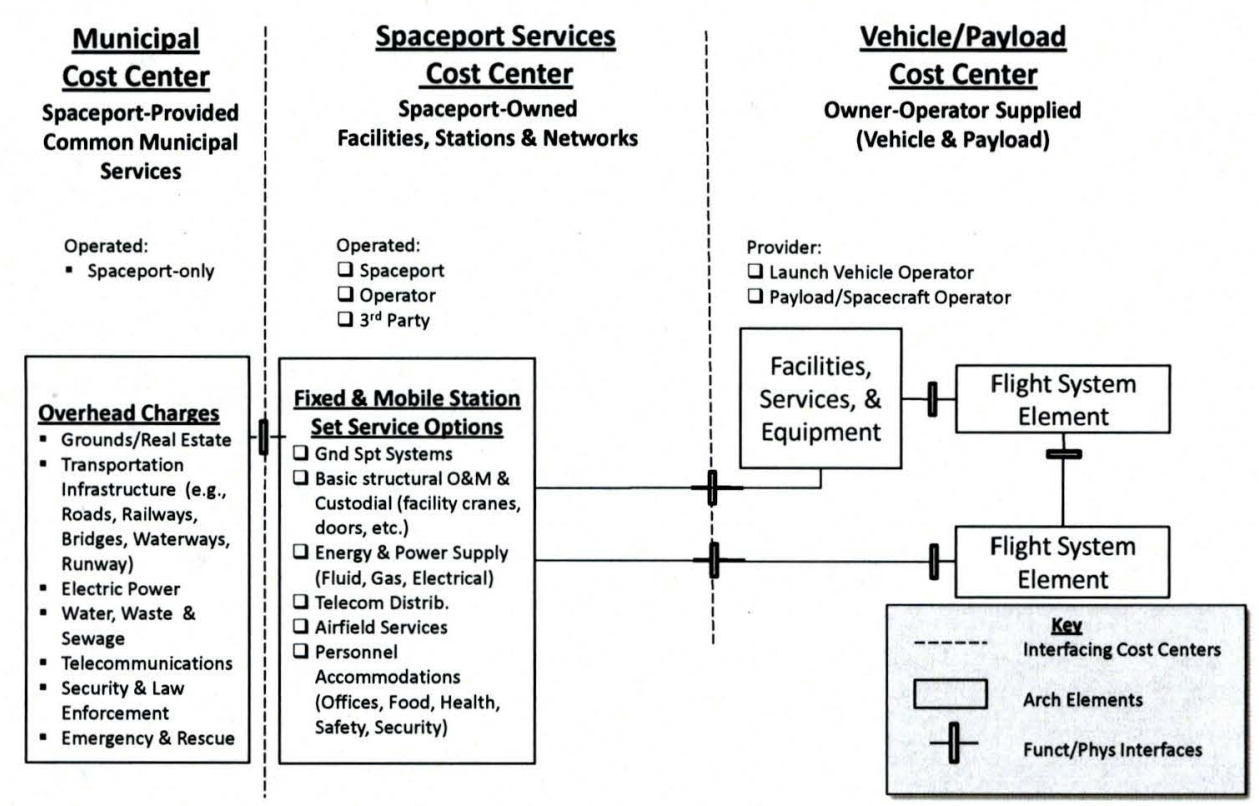

Figure 11—Compatibility of flight and ground system interfaces within a business enterprise drives cost and cycle time ${ }^{29}$ 
Key interfacing issues that drive the balance of complexity and scale, and therefore the architectural impact to affordability and productivity are:

- Service type and quantity provided from ground stations (including the launch pad station) to the vehicle, or vehicle element

- Elevation of the service at launch point in launch configuration

- External Access for any manual service operations

- Internal Access for personnel entry

- Hazards

- Vehicle command and control

Identifying some general design approaches for the flight vehicle is difficult, but some specific techniques were outlined by the Space Propulsion Synergy Team (SPST) in recent papers and in the Operationally Efficient Propulsion Systems Study (OEPSS) in 1992. ${ }^{30,31}$

B.Potential Vehicle Element Features and Improvements to Affordability and Productivity

1. Choose a level of reusability for the vehicle architectural elements

a) Reusable vehicle element that returns functionally intact

o Maintain: structural, mechanical, fluid system, electrical power system, command and data system, and software system integrity between flights

- No personnel, entry into vehicle compartments (other than crew/passenger cabins), with associated breakage of seals closed-out on the previous flight, labor-intensive re-application of coatings, thermal protection component repairs and replacements, etc.

○ No flight-by-flight airframe mechanism disassembly, re-rigging, re-alignment, re-calibration, reapplication of lubricants

- On-board power, signal path wire segments, connectors, and flight software configurations remain intact, and largely unaltered through time-consuming manual ground intervention between flights. High degree of confidence that no routine LRU troubleshooting, repair, and replacements encountered between routine flights

Pros: Avoids recurring production and assembly time and costs incurred with each flight. Highly responsive if reused without loss of functional integrity between flights.

Cons: More functions to design and certify for inbound return to Earth. May be more expensive to acquire if life cycle is short duration and/or with low system utilization.

b) Returnable vehicle element

- Focused on returning vehicle to Earth for reuse of majority of system function retention

- Some degree of functional breakage tolerated by owner-operator for: structural, mechanical, fluid system, electrical power system, command and data system, and software system replacement, troubleshooting, repair, and re-installation.

$\underline{\text { Pros: }}$ Lowers recurring production costs for entire vehicle element.

$\underline{\text { Cons: }}$ More functions to design and certify for inbound return to Earth. Substantial on-line repair and depot support required. There is less overall confidence in the overall vehicle integrity before a flight, requiring time-consuming flight-by-flight certification process. Tends to require a higher technical skill level and experience to own and operate.

c) Remanufactured vehicle element

- Focused on returning vehicle to Earth for reuse of major hardware components

- High degree of functional breakage tolerated by owner-operator for: structural, mechanical, fluid system, electrical power system, command and data system, and software system replacement, teardown, repair/replacement, reinstallation, re-acceptance.

Pros: Lowers recurring production costs for major structural element subassemblies.

$\underline{\text { Cons: }}$ More ground services and facilities for retrieval, disassembly, remanufacturing and reacceptance. Substantial off-line functional subsystem repair and depot support required. There is low level of overall confidence in the vehicle integrity before a flight, requiring time-consuming flight-by-flight certification process. Tends to require higher technical skill level and experience to own and operate. 
d) Expended vehicle element

- Focused on avoiding ground operations and infrastructure functions associated with recovery, repair and retest of system functions

Pros: Lowers recurring production costs for simple elements (e.g., expended fuel tank elements). Requires less ground services and facilities for retrieval, disassembly, remanufacturing, and reacceptance. No recurring maintenance refurbishment costs.

Cons: High recurring production cost with high variable costs for fully functional vehicle elements that dispose of the main propulsion system including engines, avionics, and other high-value hardware. Fullfunction expendable launch vehicles tend to be limited to low system utilization enterprises due to recurring production time and expense.

\section{Choose a Vehicle Element Integration Approach}

The authors chose the following mid-term example architectural approach for affordable and sustainable ETO space transportation to be compatible with mid-term business enterprises. The authors also chose integrated element architectures based on: meeting the above criteria; design, testing, production, and operations experience; and is thought to be compatible with construction and sustainment of new destinations, supports healthy growth in space development, and enables in-space assembly and operation of high-capacity, large fleet expeditions beyond Earth orbit. Characteristics of the conceptual vehicle design approach for the concept is in Figure 12.

- One (1) reusable cryogenic booster ( $\mathrm{RCB}$, or Booster) element that returns the majority of the propulsion components and systems, and other high-value subsystems functionally intact, without high-temperature thermal protection

- One (1) reusable cryogenic orbiter ( $\mathrm{RCO}$, or Orbiter) element that returns the majority of the propulsion components and systems, and other high-value subsystems functionally intact with robust thermal protection

- One (1) expended propellant tank that feeds both the Booster and the Orbiter and is released following Orbiter main engine shutdown

- Up to six (6) high thrust engines (approximately Shuttle main engine thrust class) that are common and reused for both the Booster and Orbiter; use $\mathrm{LO}_{2}$-rich, $\mathrm{LO}_{2}$-cooled ${ }^{32}$ variable mixture ratio engines

- Integrated vehicle is launched vertically; the booster and orbiter elements are landed horizontally

Figure 12-Vehicle Integration Approach for Example Concepts

\section{Choose Flight System Improvements (the Vehicle Building Blocks)}

In defining space vehicle architectures, the propulsion system and subsystem choices will have a major influence on achieving the desired goals and objectives. Fortunately, propulsion technologists have published an organized set of choices "to provide a resource of focused material for architectural concept developers to use in designing new advanced systems including college design classes, " and, "to develop insight that will effectively aid the architectural concept developer in making the appropriate choices consistent with the architecture goals." 33

a) System Integration Approach for the Example Architecture

Based on the Space Propulsion Choices - Pros and Cons, the systems integration approach has eight parts:

1. Choose the vehicle configuration and propellant tanks

2. Choose the propulsion system engine propellant feed technique

3. Choose the propellant transfer pumping concept

4. Choose turbo-pump distribution method (example is not pressure fed due to performance requirement)

5. Choose a concept for main rocket engine start/shutdown

6. Choose ignition method

7. Choose a concept for exhaust nozzle number and placement

8. Choose a propulsion compartment structural design concept

b) Non-Chemical Propulsion [Not addressed for mid-term ETO example in this paper]

c) Chemical Propulsion

Based on the Space Propulsion Choices-Pros and Cons, the chemical propulsion choices has four parts:

1. Choose the propellant type

2. Choose specific propellant considering density and performance

3. Choose monopropellant or bi-propellant combination

4. Choose a concept for cooling the rocket engine(s) 
d) Functional Integration

Based on the Space Propulsion Choices-Pros and Cons, the propulsion system functional integration choices have four parts:

1. Select a rocket combustion cycle

2. Choose a method for vehicle guidance and control steering

3. Choose a method for attitude control steering

4. Choose a level of system hardware integration among on-board propulsion, power, and thermal management functions

e) Thermal Management Integration Approach

Based on the Space Propulsion Choices-Pros and Cons, the thermal management integration choices have two parts:

1. Choose concept for tank-airframe structural integration

2. Choose concept for tank insulation approach

For a perspective of the choices for the example flight system architectures in the context of alternatives $c$, see Attachment C. For a discussion of the pros and cons of each alternative, the reader should refer to the Space Propulsion Choices - Pros and Cons. ${ }^{34}$ It presents a logical and comprehensive set of choices, but more importantly, present the pro and the con implications of these choices. A detailed list of choices selected by the authors for the examples is in Attachment $\mathrm{C}$.

\section{Step 5: Build and Size the Architectural Concept from Building Block Solutions}

The next step in the approach is to pull together the building blocks into a complete flight and ground space transportation architectural concept.

\section{A. First-Document the Ground Rules and Assumptions for the Operational Concept}

The example architectural is assumed to operate as follows:

1. Business Case

It assumes that there is a commercial and government market for operating the proposed architecture. That is, for a mid-term affordability objective of $\$ 2,200$ cost-per-kg and seat cost objective of $\$ 2 \mathrm{M}$, there is a demand for small fleets of boosters and orbiters by competing commercial operators

\section{Concept of Recurring Production and/or Supply}

Demand for flight equipment is such that a minimum 5- to 10-year airframe production demand exists for booster and orbiter airframes exist with supporting maintenance, repair and overhaul (MRO) and upgrade contracts.

\section{Concept of Recurring Ground Operations}

Ground maintenance is assumed to be a phased maintenance approach. In this approach line level maintenance for the booster and orbiter airframe is predicated on previously demonstrated dependability, and that the design life of all components is compatible with re-flight such that the vehicles do not require intrusive repairs on turnaround. Offline intermediate depot maintenance may be required of the vehicle elements on a periodic basis to address limited life items and systems recertification. Periodic and more thorough airframe inspections may be required at even longer intervals to achieve the expected airframe life.

4. Concept of Recurring Flight Operations

Operators from spaceport or off-site facilities control flight operations and operations may be monitored by other remote locations.

5. Concept of Design, Development, Test \& Evaluation $(D D T \& E) \&$ Continuous Improvement

Vehicles are assumed to be certified by ground and flight systems qualification, verification and validation test program before production commitment to allow for systems improvements to meet all the performance and affordability objectives. This includes a ground and flight test program that includes operational readiness demonstrations, similar to those required of military aerospace weapon systems and commercial aviation certification. Successful achievement of these program milestones will demonstrate to potential operators, payload users, and investors, the required level of responsiveness, maintainability, supportability, and overall system availability. Confidence in the marketplace that achieving respectable improvements in these architectural attributes can routinely be accomplished will promote growth in the space transportation industry. 


\section{B. Second-Conceptual Design of the Vehicle-to-Ground Interfaces}

1. Design the Structural, Mechanical, and Propulsion Interfaces

All propulsion and fluid interfaces connect to the ground at ground level precluding elevated umbilical connections and service towers. Connections are automated for attachment and functional verification. A singular flight hatch provides flight crew and passenger ingress/egress.

\section{Design the Power and Communications Interfaces}

All hard line power and communications services are also connected from ground level only. Connections are automated for both attachment and functional verification.

\section{Conceptual Design the Space Vehicle Architecture and Vehicle Elements \\ 1. Overall Description of Notional Configurations}

Two flight system configurations emerged from this example. Both assumed two reusable elements (a Booster and an Orbiter) with one or more drop tank expended after main engine cutoff. Both configurations fly in a parallel first stage burn (see Figure 13 and Figure 14). Flight profile is in Figure 15.

Ascent propellant is stored in an external tank for Notional Configuration 1. For Notional Configuration 2, the ascent propellant load is stored on-board ("internalized") with excess hydrogen in twin over-wing drop tanks mounted on the orbiter of a bimese" configuration. In both cases the tanks are assumed to be carried through second stage engine cutoff, much like Shuttle. In Configuration 1 alternative tank arrangements enable loading from the bottom of the vehicle stack and. Weight penalties are traded with other inter-tank, compartment, and conditioning systems for normal tandem tank-dome arrangements. The main features of interest are: the ability to load the tank from ground level, avoiding elevated services; and, reducing the reusable vehicle sizes.

Notionally, there is a Reusable Cryogenic Booster (RCB) that fires either three (3) or four (4) $\mathrm{LO}_{2} / \mathrm{LH}_{2}$ high thrust, $\mathrm{LO}_{2}$-rich variable or dual mixture ratio engines (D/VMREs), that operate at $\sim 12: 1$ mixture ratio (MR) for launch. This allows for a more compact vehicle design through a naturally higher first stage propellant bulk density. Booster and orbiter main engines are a common design. For the notional concepts, engines could also be dual mixture ratio rather than continuously variable.

The Reusable Cryogenic Orbiter (RCO) carries the payload. In the Configuration 1 there are several options for payload volumes, the exact nature and placement of which was not the focus of this effort.

* A bimese configuration is one that uses two very similar or common airframes mounted directly together. 



Figure 13- Notional Configuration 1 is a $4 / 2$ Booster/Orbiter Engine Split with $\mathrm{LO}_{2} / \mathrm{LH}_{2}$ External Tank

(Notional sizing shown in comparison with Space Shuttle launch stack)
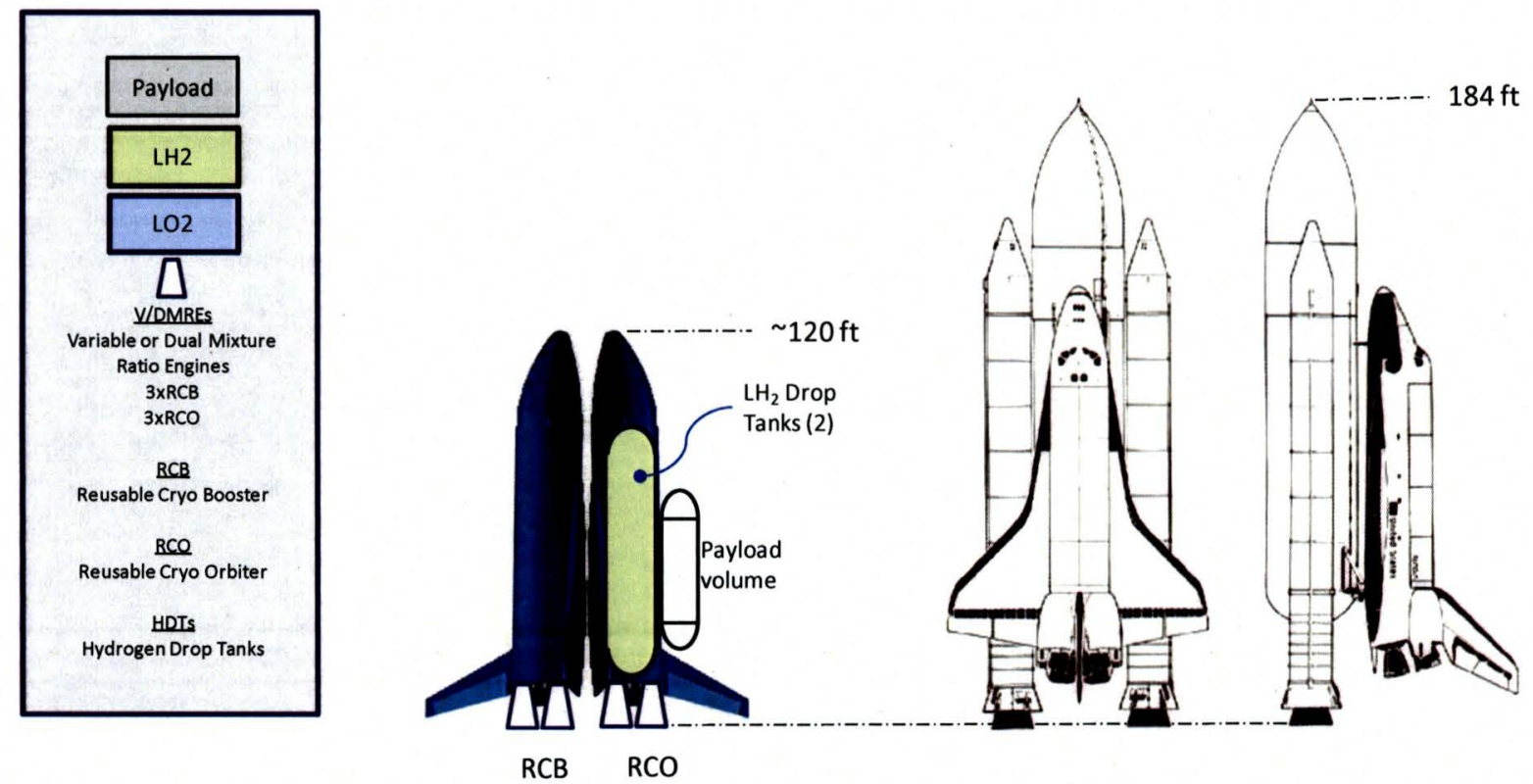

Figure 14-Notional Configuration 2 is a 3/3 Booster/Orbiter Engine Split Bimese Vehicle with Pair of Over-Wing Drop Tanks (Notional sizing shown in comparison with Space Shuttle launch stack) 


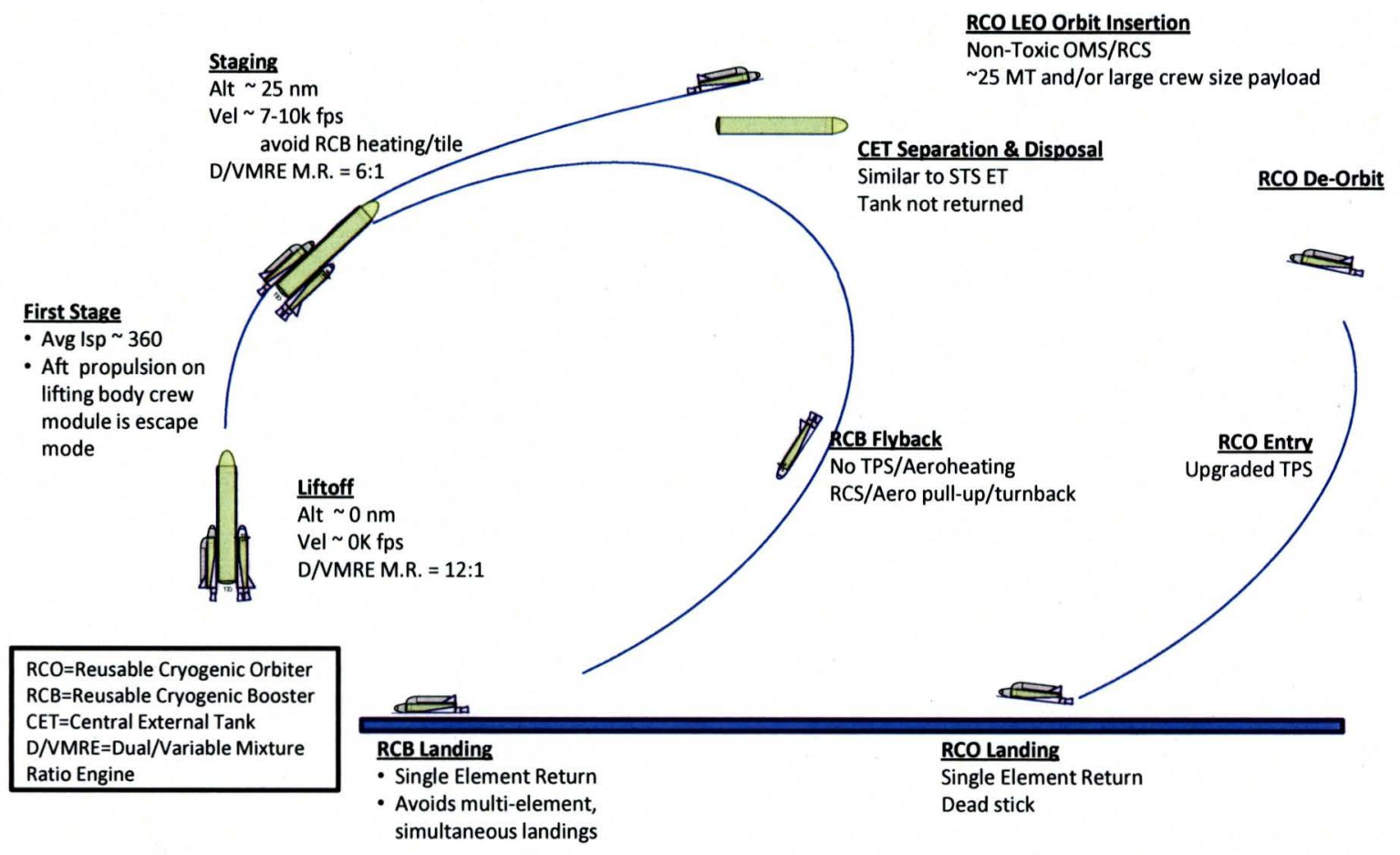

Figure 15-Notional Configuration I Flight Design

\section{Discussion of Notional Configuration 1 and 2 Conceptual Design Approach}

The following items describe the key features sought by both configurations. It should be emphasized that no recommendations are made for one configuration over the other. The two configurations are meant to demonstrate the configuration results from applying a different set of vehicle conceptual design options and constraints. The purpose was not design optimization, but design approach exploration that would allow greater levels of affordability and productivity through use of different and/or advanced technical approaches. These included:

a) Reuse of high value, functional hardware - all engines and the vast majority of all active propellant components, along with avionics, and thermal control are reused. Recurring production would be confined to static propellant tankage and LH2 feed lines.

b) Common airframe and internalized propellant tanks for Booster and Orbiter-the airframe structure and tankage are intended to be common in design to the maximum extent practical. While the orbiter requires more complex attachments for payload and external thermal protection for entry, keeping the up-front acquisition costs low is desirable. This approach may also offer business case flexibility if common, modular airframe substructure designs are defined. For example, wing and tail upgrades attached to a common fuselage, and similarly for the thrust structure to the fuselage.

c) Tank Configurations - the ground rules of this exercise constrained the arrangement of main propellant tanks to be compatible with ease of ground loading, offloading, and conditioning. Specifically, the $\mathrm{LO}_{2}$ tank volume was arranged such that it could be loaded from ground level, with short $\mathrm{LO}_{2}$ feed lines that avoid thermal conditioning complexities, water hammer, and geyser problems. For a discussion of the operational concerns associated with elevated $\mathrm{LO}_{2}$ tanks, reference OEPSS Volume IV-Design Concepts. LH2 tanks were allowed to be placed in tandem above LO2 tanks, but nested in such a way that a large interstitial space could be avoided. Alternative tank arrangements, such as concentric and nested tank arrangements, were also considered acceptable by the authors. The authors have found that highly tandem arrangements tend to create the greatest ground system burden through the creation of multiple elevated closed compartments and side-accessed ground service requirements.

d) Closed Compartment Avoidance - the ground rules of this exercise also constrained the vehicle layouts in the amount, elevation, and number of closed compartments, such as large volume inter-stage and inter-tank areas. 
Closed compartments can give rise to a number of functional subsystems that add life cycle work: added design, added development, added recurring production, and added operations. Specific Impacts include:

- Environmental control systems (ECS) due to potential for hazardous gas accumulation

(requiring gaseous $\mathrm{N}_{2}$ purges), personnel entry (requiring conditioned air)

- Hazardous gas detection systems

- Volume for additional subsystem components; in turn driving personnel compartment entry and closeout burden

- Side umbilical connections to the ground

- Internal personnel access kits

e) Auxiliary Propulsion and Power Sources Drawn from Main Propellant Tanks-In order to integrate the maximum amount of functions into the minimum amount of hardware, maximum use is made of the stored energy in the main tanks. Auxiliary propulsion functions in this example include the potential need for a booster rocket back maneuver and exo-atmospheric attitude control; on-orbit maneuvering and attitude control for the orbiter; electrical power generation from turbo-pump tap-off to drive electric-powered actuators for aero-surface and thrust vector control (TVC); and potentially for on-board fuel cell power (however, specific power system definition was not explored). All of these functions for the booster and the orbiter are assumed to draw from on-board $\mathrm{LO}_{2}$ and $\mathrm{LH} 2$ tanks.

f) Integrated Modular Main Propulsion System - is a parallel network system consisting of a propellant ring manifold that allows the turbo-pumps to feed all thrust chambers and to operate independently from any given thrust chambers. In other words, the power head of the engine, which normally has a pair of turbo-pumps co-located and packaged onto the thrust chamber to keep the high pressure runs on the output side of the pumps small, are decoupled in the integrated modular approach. New materials and innovative fabricating techniques have emerged in recent years make this concept worth pursuing from an engineering standpoint. Advantages include: a higher degree of fault tolerance, particularly for a "turbo-pump out" condition; and greater ease of implementing variable mixture ratios (either discretely variable by turning pumps on and off, or continuously by varying their relative speeds). Potential also exists to lower the overall main propulsion-engine system mass through a more integrated, modular design approach. ${ }^{35}$

\section{Conceptually Design the Ground Architecture and Ground System Elements}

Just as the example vehicle architectures were conceptualized from the interface characteristics among the flight elements and with the ground functions, the ground architecture was derived from the same interface characteristics to be compatible with the vehicle concept. The general idea was to adhere to a launch architecture supplying only the necessary vehicle services. A "cleaner" launch pad was derived by applying the same interface principals applied in the vehicle configuration design. Conceptually, the approach was simplifying the flight and ground architectures simultaneously. The simplification approach (see Figure 16) graphical compares the system characteristics of historical space flight architectures (such as Launch Complex 39) to one envisioned for the paper examples. More explanation of this can be found in the paper titled "A Systems Approach to Developing an Affordable Space Ground Transportation Architecture using a Commonality Approach," by Garcia, et al. ${ }^{36}$ 


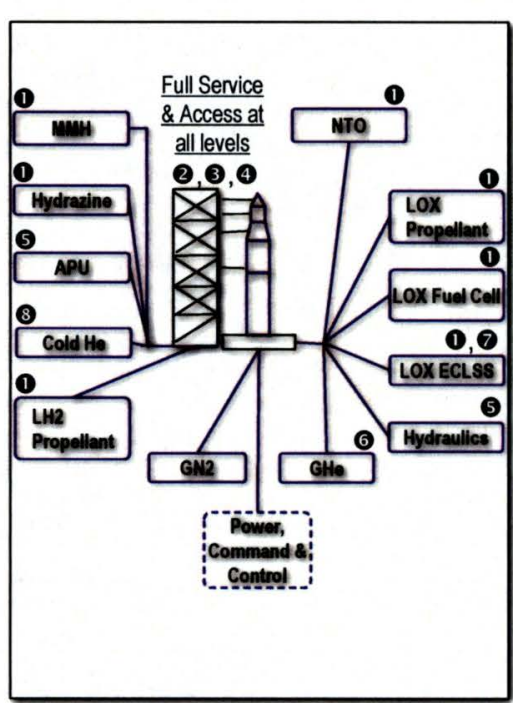

Less Affordable \& Productive
Example Techniques for Improving for Architectural Affordability*

1. Main propellants LO2/LH2 only (No toxic propellants; power \& auxiliary propulsion functions fed from main propulsion tanks)

2. Avoidance of closed compartments

3. Services provided from ground level (or vehicle zero-level)

4. Tank arrangements avoid long propellant feed lines

5. Use of electric powered actuators

6. Simplified pneumatic and conditioning requirements (No Helium system required)

7. ECLSS Oxygen derived from main propulsion tanks

8. Thermal conditioning simplified (no cold Helium, anti-geysering, pogo suppression systems required)

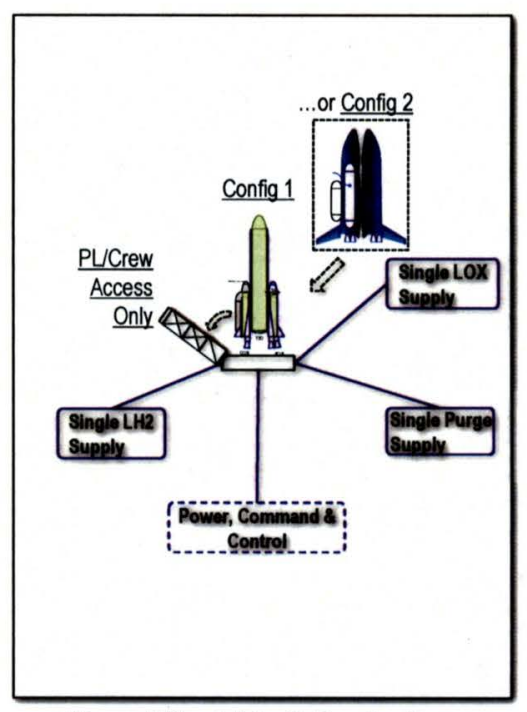

More Affordable \& Productive

Figure 16-General approach for architectural simplification to achieve greater affordability and productivity

\section{E. Configuration Results-Pros, Cons, and Observations}

The feasibility of the configurations was determined through rough-order-of-magnitude level of analysis (basic rocket equation with ideal delta-v's, rough-order masses, volumes and lengths). More thorough trajectory, weights and sizing, propulsion, and thermal analyses were not performed. A table of rough-order vehicle performance results is provided in Table 2 .

Table 2-Comparison of vehicle architectures

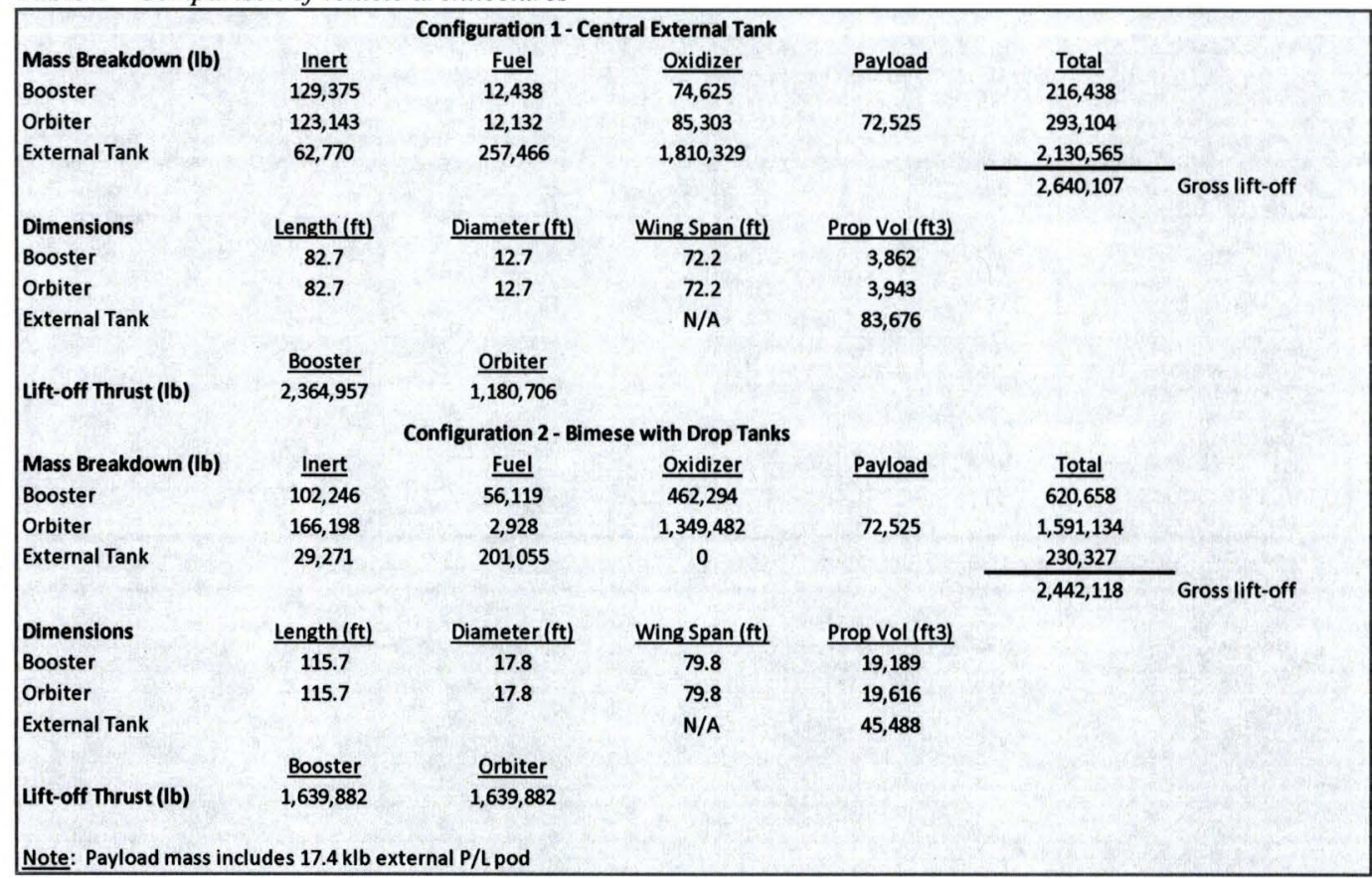

American Institute of Aeronautics and Astronautics 080112 


\section{Notional Configuration 1-Reusable Booster-Orbiter Combination with Central External Tank}

Configuration 1 takes the approach of externalizing the ascent propellant required of both the Booster and the Orbiter, and internalizing a small amount required for booster return in the RCB, and for on-orbit/de-orbit delta-v and attitude control on the RCO.

Initially, tandem tank arrangements (i.e., both tanks lined up along a common longitudinal axis) were considered. Placement of the $\mathrm{LO}_{2}$ tank in a tandem arrangement presented a number of complexities, however. If the $\mathrm{LO}_{2}$ tank is placed forward of the $\mathrm{LH}_{2}$ tank, then the system complexity (both flight and ground) grows, adversely affecting the system affordability and productivity. If the $\mathrm{LO}_{2}$ tank is placed aft of the $\mathrm{LH}_{2}$ tank, static stability and control problems occur due to the thrust/center-of-gravity (c.g.) characteristics. Bear in mind that the density of $\mathrm{LO}_{2}$ is far greater than that of $\mathrm{LH}_{2}$, resulting in the overall $\mathrm{LO}_{2}$ load being far heavier than the $\mathrm{LH}_{2}$ load for ascent; even though the $\mathrm{LO}_{2}$-rich mixture ratio in first stage is designed to keep the $\mathrm{LH}_{2}$-to- $\mathrm{LO}_{2}$ volume ratio low. Canting, or providing an angled thrust structure that naturally points inward toward the c.g., and other techniques were found to alleviate the static stability concerns, particularly at booster separation.

One alternative approach considered by the authors, inspired by the OEPSS Volume IV-Design Concepts, was to use a concentric $\mathrm{LO}_{2}$ annulus jacketed around a cylindrical $\mathrm{LH}_{2}$ tank. The stand-alone, tank-only masses compare favorably to traditional cylindrical tanks, and the inner annulus wall has to be designed to accept compression loads. However, when considering the total external tank element structure, where trades must be made against not only the tank mass, but intertank masses ( $20 \%$ of the dry mass of the Space Shuttle External Tank), the dry mass penalty appeared to be promising to achieve a simpler vehicle to operate.

The concentric external tank concept would require engineering and technology investment, but one that has potential application in the mid-term, and its use may extend beyond ETO application. Uses for concentric $\mathrm{LO}_{2} / \mathrm{LH}_{2}$ storage tank arrangements have great potential for in-space architectures, offering thermodynamic and stage packaging efficiency benefits. ${ }^{37}$ These configurations were examined in the Operationally Efficient Propulsion System Study (OEPSS) during the early 1990s, and documented in OEPSS Volume VI: Space Transfer Propulsion Operational Efficiency Study Task. ${ }^{38}$

Another potential arrangement uses a tandem-nested arrangement with the $\mathrm{LO}_{2}$ tank aft and the $\mathrm{LH}_{2}$ forward. However, to avoid a closed compartment, the $\mathrm{LH}_{2}$ aft tank structure conformed to the $\mathrm{LO}_{2}$ tank forward structure (i.e., "nested).

With either arrangement (concentric or tandem-nested), the vehicle is fueled through the reusable elements from the ground (or, "zero-level") of the integrated vehicle stack. Both propellants in the external tank are fueled and purged with nitrogen from the aft (much as the Shuttle external tank was fueled). The purge is vented overboard out the top. All this eliminates the need for long, insulated feed lines for both $\mathrm{LO}_{2}$ and $\mathrm{LH}_{2}{ }^{*}$. In total the benefits include: greatly simplified design opportunities for loading that eliminate a number of conditioning requirements and their resulting subsystems, including: requirements associated with feed system and anti-geysering complexities; reduction in mass due to simplified feed system approach; and trading intertank mass for alternatively arranged tank masses.

2. Notional Configuration 2-Bimese with Over-Wing Hydrogen Tanks

Configuration 2 takes the approach of externalizing only the ascent hydrogen propellant required of both the booster and the orbiter, and internalizing oxygen within the Booster and Orbiter. Liquid hydrogen storage tanks are also internalized in both reusable elements: for booster return on the RCB; and for on-orbit/de-orbit delta-v and attitude control on the RCO.

The tank arrangements in this configuration are tandem with the $\mathrm{LO}_{2}$ tank aft to avoid the operational complexities and concerns. To avoid large, complex inter-tank areas, this configuration uses the nested $\mathrm{LH}_{2} \operatorname{tank}$ approach, whose aft dome is inverted to conform to the $\mathrm{LO}_{2}$ forward tank dome, or vice versa. Use of a common bulkhead is avoided to alleviate operational complexities associated with thermal control and conditioning during loading and off-loading operations. The interstitial gap between the $\mathrm{LH}_{2}$ and $\mathrm{LO}_{2}$ tanks are minimized to a very small area that can accommodate tank expansion and contraction, and would use an insulation technique that is factory-sealed, and avoids any routine launch site servicing equipment or operations. This approach transfers $\mathrm{LH}_{2}$ for ascent through a pair of over-wing tanks that are "dropped" off after the RCO main engine cutoff event. The static stability and control margin of Configuration 2 also appears more favorable. The reusable vehicles tend to be

\footnotetext{
* The tandem-nested arrangement does require an LH2 feed line, but its length is minimized due to the fact that it traverses a shorter $\mathrm{LO}_{2}$ than would an $\mathrm{LO}_{2}$ line traverses a longer $\mathrm{LH}_{2}$ tank. Further, the water hammer/geysering effects of long-run $\mathrm{LO}_{2}$ feed lines are nearly non-existent for the shorter $\mathrm{LH}_{2}$ feed line.
} 
larger in size than those of Configuration 1, although, smaller than traditional bimese, two-stage-to-orbit configurations.

\section{Staging velocity-Mixture Ratio (MR) relationship}

Since these notional configurations were not run through sophisticated trajectory and sizing analyses, the staging velocity for the reusable booster was simply constrained to an ideal delta-v from 7,000 to 10,000 feet-per-second (fps) in order to approximate the ability of the RCB airframe to avoid a high temperature thermal protection system. Similarly, a lower bound of $\sim 7,000$ fps was used to imply a low staging altitude and dynamic pressure for glide back return and performance constraints.

The staging of the booster assumed that the main engines would continue to burn, supplied by the on-board tanks for a rocket-back turnaround maneuver that ended in an un-powered glide return to the launch site (as was also assumed for Configuration 1). Further analysis and optimization may show $t$ un-powered glide back is feasible.

It was noted that the staging velocity and mixture ratios have a relationship that could contribute to both the performance and complexity of the vehicle and system architecture. Follow-on advanced concept and technology architecture studies appear desirable, given the characteristics observed by the authors of the staging velocity and mixture ratio relationships and the design options that could be considered.

\section{Thermal Protection and Tank Insulation}

Concerns for tank icing/orbiter debris impact in a parallel element configuration would be addressed through the design and development safety assessment and review process, including conservative mass margins for existing and/or advanced technology solutions (e.g., hardened orbiter TPS, tank insulation, purges of sensitive areas). A higher degree of vehicle flight testing than the short, four-flight program for Space Shuttle, is achieved through far lower marginal flight costs and inherently higher flight rate capability. If this were not so, the architecture fails the design objectives. Planning up front for a thorough flight test period, rather than prematurely deploying the system, offers adequate opportunity for performing engineering design corrective action.

\section{Abort Scenarios}

Detailed abort analyses were not performed for these early notional configurations. However, the authors feel that the example configurations exhibited inherent flexibility for accommodating engine-out. If employing the integrated modular propulsion system approach, where a redundant set of turbo-pumps are decoupled from the power heads to feed the thrust chamber, then abort probabilities and accommodation of "turbo-pump out" scenarios would be favorable for accommodating larger abort regions and margins."

\section{Step 6: Estimate Magnitude of Life Cycle Improvements}

Finally, the architectures are assessed for life cycle cost and productiveness. Tools must be chosen that can provide insight across the architectural elements (design, testing, production, as well as ground and flight operations). Additionally, assessments of vehicle performance and insight into system cycle time are required.

The ACT prototype was used to approximate and compare the following:

- Total life cycle cost

- Annual affordability

- Cost per pound

- Cost per seat

- Cost per flight (average)

- Total payload mass throughput.

Although ACT is not a deterministic model, it does use characteristics (parametric factors) of the architectures/systems being compared to produce important system outcomes (figures-of-merit). The outcome figures-of-merit provide the designer with information on the relative affordability of different configurations. ${ }^{39}$ For the examples an assessment of relative differences between the Space Shuttle controlled interfaces ${ }^{40}$ and Notional Configuration $1 .^{\dagger}$

\footnotetext{
* For a detailed treatment of this and other fault tolerant benefits and quantification of the reliability of an integrated modular propulsion design approach, consult OEPSS Data Book IV - Design Concepts, RI/RD90-149-4.

${ }^{t}$ Configuration 2 differences were relatively minor compared to Configuration 1 , and are not documented.

22

American Institute of Aeronautics and Astronautics 080112
} 


\section{Life Cycle Comparison Scenario}

The scenario comparison was run to produce single-string architecture results in order to understand achievement of the objectives summarized in Figure 9. The scenario inputs to the proof-of-concept version of ACT used were as follows:

- Total life cycle set to 30 years of operation + development \& acquisition period

- Depth of Qualification, Verification \& Validation ground and flight test program set to "Medium" for Shuttle and "High" for the examples. The "High" setting in ACT indicates a longer and more expensive ground and flight test program to allow for system design changes required to meet the recurring production and operations affordability and annual flight rate and payload delivery objectives.

- Flight rate demand on the architecture was held to no more than 20 flights-per-year

- Fleet size held to single string (one reusable vehicle ship set: one Orbiter and SRB set for Shuttle, and one $R C B / R C O$ ship set for the example configuration)

- Total payload mass assumed to be 55,125 lbs. (25MT); for both Shuttle and the examples

Additionally, a system-by-system and interface-by-interface comparison was made, along with assessments of overhead factors. This resulted in establishment of parametric factors that fed the main affordability algorithm (see Figure 4). The interface comparison, for example, revealed a reduction in controlled interfaces from 667 for Space Shuttle, down to approximately 375 to 400 for Configurations 1 and 2 (depending on specific design and technology assumptions). More importantly, the interfaces that remained were of a less complex nature, lacking in ground infrastructure and operations overhead associated with toxic hazardous systems and closed compartments.

\section{Comparison Results Summary}

The overall results for the comparison Notional Configuration 1 to Shuttle are presented in Figure 17 in a similar fashion as that shown in Figure 4. It should be emphasized that the Shuttle results are for a theoretical single-string operation. Therefore, the Shuttle annual costs will appear lower than that achieved for the entire fleet, and the flight rates are likewise lower. This also results in a much higher cost-per-pound and cost-per-seat than normally attributed to the entire operational fleet.

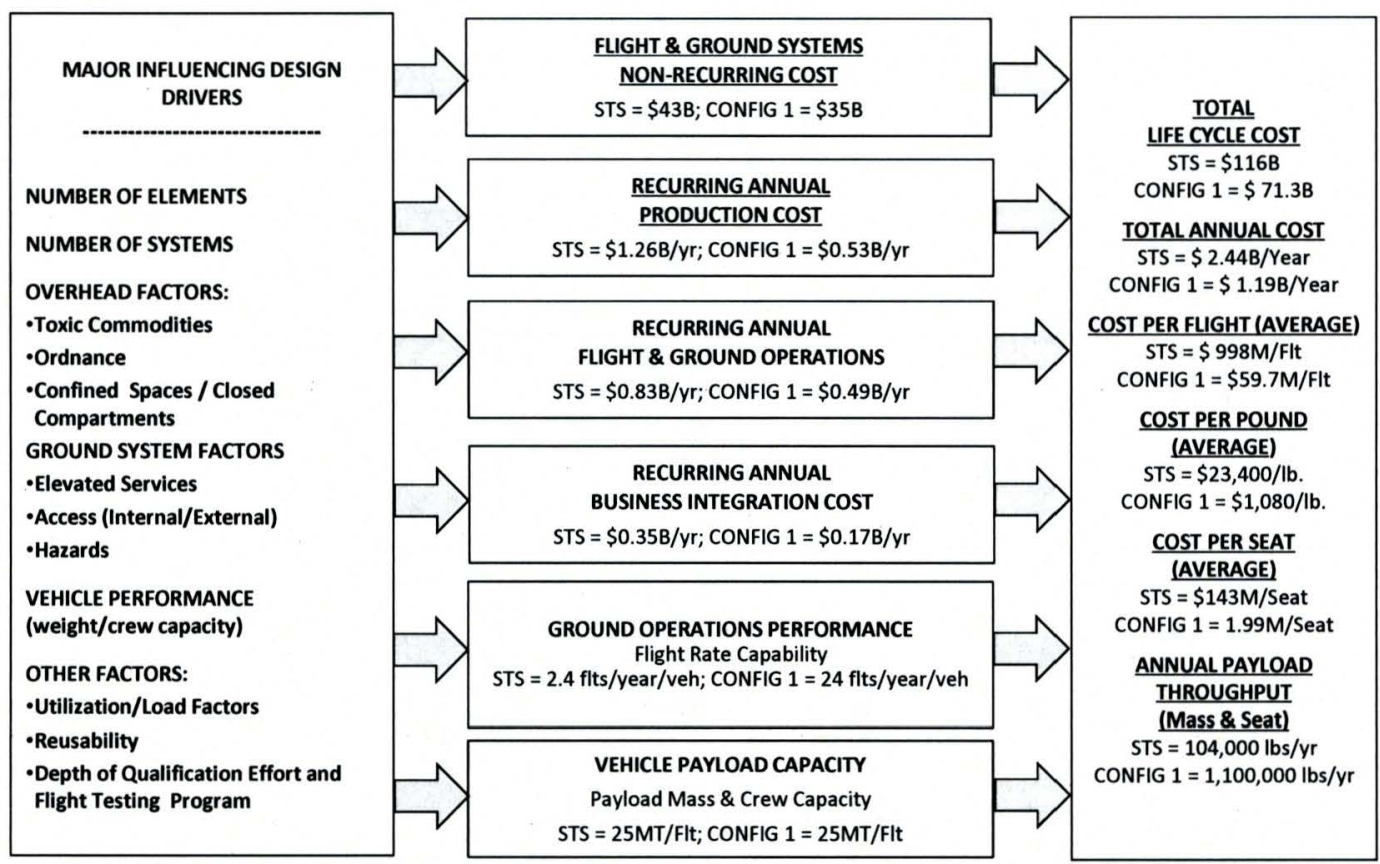

Figure 17-Summary of Life Cycle Affordability Results for Notional Configuration I-Based Architecture

(Based on Shuttle-anchored comparison)

*ACT in-house prototype Excel file version, v.0.2r1, A_C_T_R6_Sensitivities_06212012. 
3. Sensitivities to System Design Complexity and Flight Rate Utilization

A sensitivity graph is also provided in Figure 18 that shows how the cost-per-pound and annual payload throughput vary with the number of controlled subsystem interfaces.

Figure 17 also shows that in order to meet the farther-term throughput objective of 1,000 MT/year, the architecture needs to cut its complexity in half, and that to also achieve the $\$ 100 / \mathrm{lb}$ objective, the complexity needs to be cut in half again, to fewer than 100 controlled interfaces.

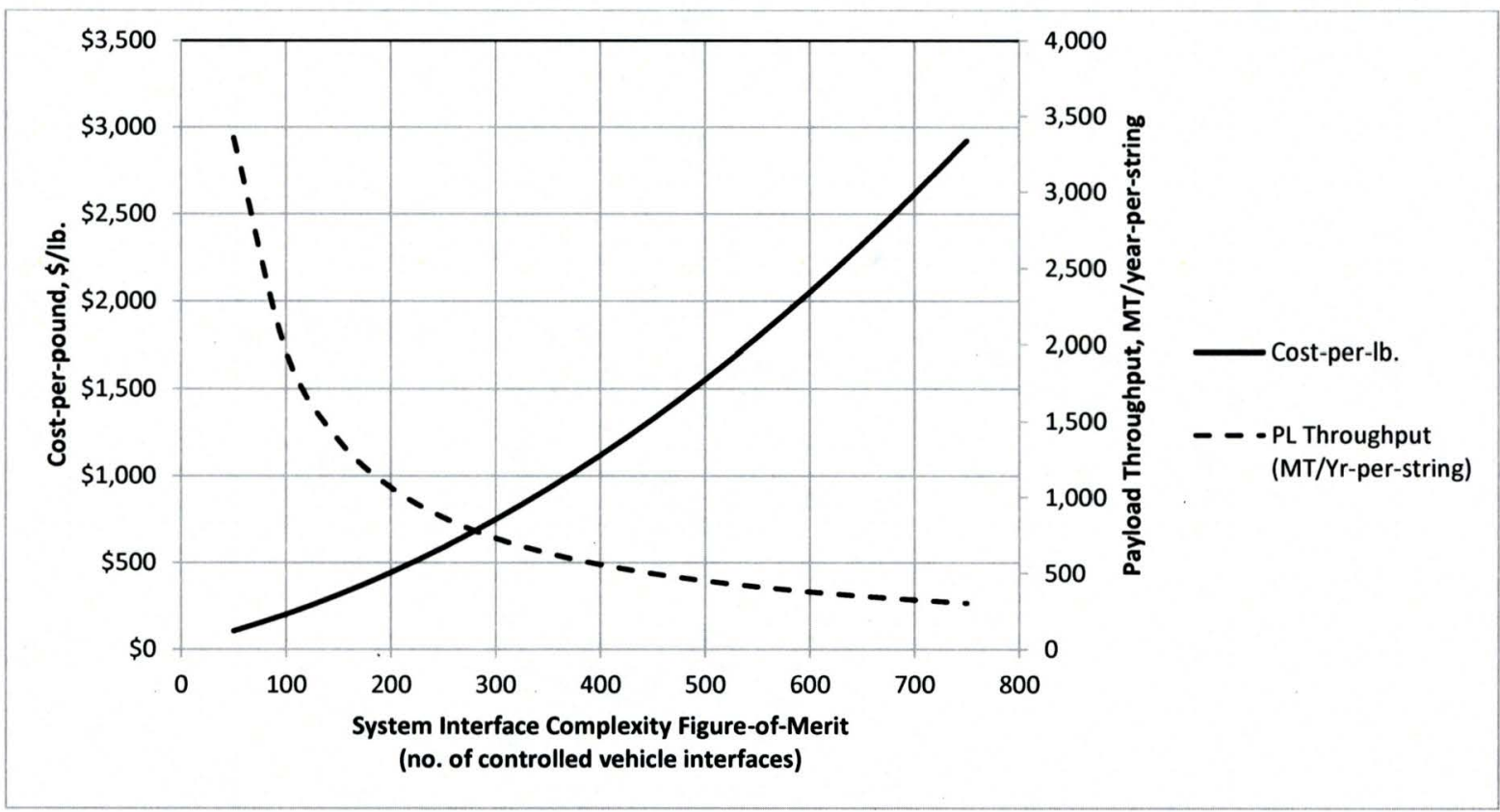

Figure 18 Example of Sensitivity of Affordability and Productivity to System Complexity (for the given life cycle scenario and Notional Configuration 1) 


\section{Summary}

This paper describes a structured conceptual design approach, with examples, for achieving more affordable, productive, and sustainable space transportation architectures. An example set of needs for future space business enterprises were first identified in Section III that act as mid- and farther-term requirements on space transportation architecture. This allowed a structured outline to be created in Section IV for quantifiable space transportation goals based on existing systems. Using a comprehensive life cycle algorithm (Figure 4) for synthesizing architectural affordability and productivity, a set of architectural objectives was created. The needs, goals, and objectives were summarized in Figure 9.

Formulation of design criteria is in Section V, these criteria provided in the context of architectural functions across the life cycle. This provided a foundation for creating a set of conceptual design "building blocks" centered on the compatibility of flight-to-ground system functional interfaces. The basic building blocks were chosen with the aid of the SPST's propulsion system selections menu in Attachment C. Results of the authors selections are in Section VI.

Two example flight architectures were derived independently by the authors from the building blocks and are summarized in Section VII. Affordability and productivity comparisons of these advanced configurations to the Space Shuttle were accomplished with a prototype ACT currently under development at the Kennedy Space Center. Sensitivities to architectural complexity were briefly explored relative to the accumulation and complexity of controlled element, system, and subsystem interfaces with the ground infrastructure. The result was achievement of the overall affordability and productivity objectives, including $\$ 1,000 / \mathrm{lb}$ at a production level of 20 flights-per-yearper-vehicle delivering 25MT to LEO. Further, mathematically consistent allocation of lower-level architectural elements can be demonstrated. For example, objective O-1A Recurring Production/Ops Cost $<\$ 1.1 \mathrm{~B} / \mathrm{Yr}$ (fixed + one string of assets) in Figure 9 can be allocated into three segments per the ACT results found in Figure 17:

- Recurring Production Cost

- Recurring Flight \& Ground Operations Cost

- Recurring Business Integration Cost

$$
\begin{aligned}
& <\$ 530 \mathrm{M} / \text { year (fixed }+ \text { one string of assets) } \\
& <\$ 490 \mathrm{M} / \text { year (fixed }+ \text { one string of assets) } \\
& <\$ 170 \mathrm{M} / \text { year (fixed }+ \text { one string of assets) }
\end{aligned}
$$

Compatibility with the design of the ground architecture was accounted for and briefly discussed in Section VII.D. A more thorough treatment of the ground architecture design approach can be found in the $48^{\text {th }}$ Joint Propulsion Conference technical paper, titled A Systems Approach to Developing an Affordable Space Ground Transportation Architecture using a Commonality Approach, by Garcia, J., et al. ${ }^{41}$

\section{Conclusion}

The structured approach outlined in the paper appears capable of bringing forth viable space transportation architectures. No attempt was made to discriminate or "down select" between those configurations. The purpose of the example configurations was to demonstrate a structured approach in achieving affordability and productivity architectures across the life cycle, rather than optimizing one in particular and focusing on its cost and schedule during acquisition phase.

However, it can be concluded that with the proper design focus, and with only a "notional" understanding of these configurations, more engineering and technology work can, and should, begin so that the technical building blocks described become available to vehicle designers in the future. 


\section{Acknowledgements}

The authors wish to acknowledge the many hours by Space Propulsion Synergy Team professionals who have volunteered their time, treasure, and talent over the many years of its existence. Without their many useful products, this paper could not have been undertaken. Carey McCleskey, the lead author, would also like to thank the staff of the Engineering and Technology Directorate of the Kennedy Space Center, and in particular, Mr. Timothy Bollo, for technical and editing guidance, as well as his experience and substantive contributions in the subject. 


\section{Attachment A \\ Summary of Space Shuttle Ground Operations Work}

(Source: NASA TP-2005 211519)

1. Excessive Unplanned Troubleshooting and Repair

- Flight and ground system dependability (i.e., the hardware design life and flight element reliability in relation to total parts count)

- Flight and ground system complexity manifested through high parts count in components, subsystems, and redundancy management techniques

- Lack of an effective means for balancing ground safety and maintainability while achieving flight safety objectives

- Lack of an effective means for implementing design corrective actions and continuous improvement

2. Complex Assembly, Handling, Access, and Mating

- Number of launch-site-installed subsystems and components per flight element

- Number and complexity of interfaces across assembled flight elements

- Number and frequency of reusable flight element modules and components requiring disassembly and/or reassembly (SSMEs, OMS/RCS pods, RMS, etc.)

- Number of single-use, limited-life components requiring assembly and access

- Decomposition of design functions discourages well-integrated design processes and resulting products proliferates hardware without regard to recurring assembly operations, ground assembly, and handling infrastructure impact

3. Excessive Flight System Servicing

- Number and type of different fluid commodities requiring routine servicing and separate flightground interfaces

- Number of limited-life items requiring routine removal, replacement, and functional verification (relates to design life issue)

- Decomposition of design functions discourages well-integrated design processes and resulting products, duplicating and proliferating hardware without regard to recurring flight system servicing operations and ground servicing infrastructure and logistics impacts

4. Lack of Demonstrated System Dependability and Resulting Functional Verification

- Lack of demonstrated operational reliability (i.e., routine system operation without need for functional restoration between flights)

- Over-redundancy in design to overcome lack of inherent reliability relative to the space transportation system operating environments

- Number of critical flight functions requiring functional verification

- Amount of reusable flight element disassembly and reassembly, and amount of expendable flight item assembly resulting in the requirement for recertification prior to each flight commitment

- Amount of automation employed in the system-both flight and ground elements

5. Excessive Facility and Equipment Preparation and Refurbishment

- Ground system dependability (i.e., design life and hardware reliability in relation to total parts count)

- Insufficient ground launch system design life to withstand the induced launch environment for frequent, routine launches

- Number of separate GSE items to support routine operations, driven in turn by flight systems design complexity

- $\quad$ Lack of an effective means for balancing ground safety and maintainability

6. Complex, Customized Payload Integration With Flight Vehicle

- Unique vehicle payload accommodations that are customized for each flight during routine on-line operations-by design

- Large number of flight-unique, vehicle-provided services to the payload that drives on-line operations (e.g., lack of payload center-of-gravity and weight margin)

American Institute of Aeronautics and Astronautics 080112 


\section{Attachment B}

Functional Systems Breakdown Structure (F-SBS) - Top-level Functions (Reference SPST Joint Propulsion Conference Technical Paper)

Earth-to-Orbit (ETO) Architectural Element Functions

1.1 Vehicle Element (e.g., Booster, Orbiter, Payload element, repeat as needed for elements)

1.1.1 Airframe Structure \& Mechanisms (For Interfacing Functions - See 1.2 Group Functions)

1.1.2 Propulsion

1.1.3 Power Management

1.1.4 Thermal Energy Management

1.1.5 Guidance, Navigation and Control

1.1.6 Communications, Vehicle Systems Control and Health Management

1.1.7 Life Support

1.1.8 Environmental and Safety Management

1.2 Vehicle Element Integration/Separation (Booster, Orbiter element)

1.2.1 Element-to-element structural attachment

1.2.2 Element-to-element communication and data transfer

1.2.3 Provide integrated vehicle control function

1.2.4 Provide electrical power transfer

1.2.5 Provide monitoring \& control of safe environment between elements

1.2.6 Element-to-element separation

1.2.7 Element-to-element servicing in space

1.2.8 Provide transfer of payload capability

1.3 Ground Infrastructure Element(s) for ETO architecture

1.3.1 Flight element preparation and/or turnaround for flight

1.3.2 Payload element production, preparation and/or turnaround for flight

1.3.3 Integrate elements and payloads for flight

1.3.4 Monitor and manage flight from authorized, controlling ground location

1.3.5 Land and/or recover flight elements and payload at compatible ground location

1.3.6 Ground traffic control and flight operations support and safety management

1.3.7 Ground infrastructure support and management for ETO architecture 


\section{Attachment C \\ PROPULSION SYSTEM SELECTIONS FOR EXAMPLE VEHICLE CONCEPT}

\section{A.System Integration Approach for the Example Architecture}

1. Choose the vehicle configuration and propellant tanks

Vertically-tandem $\mathrm{LO}_{2}$ tank forward/fuel tank aft

$\square$ Tandem fuel tank forward/ $\mathrm{LO}_{2}$ tank aft

Rationale: Preferred configuration for vehicle ascent static stability. However, tends to drive need for common/nested bulkheads that, in turn, are used to avoid excessive stack height and inter-tank mass, as well as inter-tank interstitial areas requiring additional purges, and other design and operations complexities.

■ Parallel fuel and $\mathrm{LO}_{2}$ tanks

Rationale: Preferred configuration from cost and operational performance (flight rate capability). Complies with need to load propellants from ground level to avoid complex, functional towers and umbilical connections. Also, eliminates need for added $\mathrm{LO}_{2}$ geysering, pogo, bleed and recirculation system design complexity and weight, as well as added system operation, maintenance and logistics. Avoids long chill down procedures due to thermal management issues associated with long $\mathrm{LO}_{2}$ feed lines.

- Hybrid fuel and $\mathrm{LO}_{2}$ tanks; e.g., toroidal/cylindrical combination

Hybrid fuel and $\mathrm{LO}_{2}$ tanks, e.g. oxidizer tank within fuel tank both with external access for feed system

■ Turbo-pumps

2. Choose the propulsion system engine propellant feed technique

Rationale: High engine performance required of vehicle architecture due to high payload throughput requirement.

․ Tank pressure transfer

口 Reciprocating pumps

Electric motor-driven pumps

3. Choose the propellant transfer pumping concept

Pumps integrated with combustion components

$\square$ Pumps integrated with propellant tanks (located in/near tank sump interface)

$\square$ Pumps mounted on vehicle structure separate from engine combustion hardware

Rationale: Preferred location of turbo-pumps is at base of tank at the tank interface for more rapid and dependable thermal conditioning of main propulsion system engines. Added high pressure line weight is outweighed by added operability and design simplicity, if adequate mass margin adequately accounted for in early conceptual design phase. The historical V-2, Redstone, Jupiter, and Atlas configurations (Atlas I and II) operated with the pump package separate from the power head (i.e., combustion chamber/nozzle).

4. Choose turbo-pump distribution method (example is not pressure fed due to performance requirement)

- One turbopump set, one thrust chamber assembly (one-to-one)

- One turbopump set that feeds multiple thrust chamber assemblies (one-to-many)

- Multiple turbopump sets that feed one thrust chamber assembly (many-to-one)

$\square$ Multiple turbopump sets that feed multiple thrust chamber assemblies (many-to-many)

Rationale: Preferred in a case where numerous combustion chamber/nozzles are required in the architecture. Fault-tolerant pump package feeds, through high pressure manifold distribution, multiple combustion chamber/nozzles to provide a more robust main propulsion system to pump failures without loss of vehicle thrust (which is a result of turbopump failures occurring with pumps integrated and dedicated to a singular engine. Added high pressure line weight is outweighed by added operability and design simplicity, if adequate mass margin adequately accounted for in early conceptual design phase.

$\square$ Integrated multiple rocket engine/vehicle control component versus dedicated engine controller components

Rationale: Fault-tolerant engine controllers feed redundant pump package combustion chamber/nozzles to provide a more robust main propulsion system to pump, sensor, and valve failures without loss of vehicle thrust (which is a result of dedicated engine controller failures occurring on designs that dedicate a 
controller to a singular engine. Added cabling weight is outweighed by added operability and design simplicity, if adequate mass margin adequately accounted for in early conceptual design phase.

5. Choose a concept for main rocket engine start/shutdown

Fast ramp start

$\square$ Soft start with ramp to initiation of main stage

Rationale: Avoids adverse inlet fluid dynamics that either compromise system life for reusable engines, or adds excess mass (larger lines and heavier systems) to propulsion system design to make the design robust. Softer starts avoid turbo-pump bearing skidding, and other turbopump component wear issues. Also, avoids frequent engine removals, and unplanned troubleshooting and repair.

Fast shutdown

Soft shutdown from main stage

■ Tank head start

Rationale: Avoids added system operational and ground support infrastructure complexity of groundsupplied turbine spin start.

口 Turbine spin system

Hypergolic expendable cartridge system

口 Pyrotechnic expendable cartridge system

6. Choose ignition method

- Hypergolic ground supplied system

$\square$ Augmented spark igniter system (sometimes referred to as torch system)

Rationale: Avoids added requirement for a ground-supplied turbine spin engine start system. Turbine spin system adds system design, operations, and support complexity, as well as dependability issues.

\ Alternative ignition techniques for the augmented spark igniter system - microwave, laser, or hot-wire ignition

Rationale: For advanced systems, simpler lighter weight, and more dependable ignition systems are desired. For example, consider qualifying and certifying emerging technologies such as acoustic resonant igniters

7. Choose a concept for exhaust nozzle number and placement

$\square$ Use center engine nozzle to help control ascent exhaust re-circulation heating environment

Rationale: Consider for simplifying base thermal protection, but balance with potential to create pogo problem, depending on engine mounting approach relative to aft tank dome.

$\square$ Only use ascent rocket engine nozzles thrust directly through structure to avoid support deflection during ascent.

Rationale: Consider for engine mounting approach carefully to avoid any requirement for a dedicated pogo suppression system.

8. Choose a propulsion compartment structural design concept

U Use aft closed-compartment with base heat shield and flat-plate base drag

$\square$ Provide aerodynamic vehicle aft end to allow open thrust structure and no base heat shield.

Rationale: Avoid closed compartment to avoid ground-supplied environmental control systems purges and air-to-GN $\mathrm{N}_{2}$ changeover operations for ground personnel compatible maintenance access environments (air) vs. flight environment configuration compatibility (inert $G N_{2}$ ). Avoid hazardous gas detection systems for closed, combustion hazard potential. Also, creates opportunity for added ground maintenance activity by design, once closed compartments creep into architecture during early concept definition. Requires steep ground operations overhead by requiring destroying structural integrity through routine compartment hatch removals, installation of personnel platforms, lighting, purge setups, and then reverse work (removals and closeouts). 


\section{B.Non-Chemical Propulsion Choices [Not addressed for mid-term ETO example in this paper]}

\section{C.Chemical Propulsion Choices}

Based on the Space Propulsion Choices-Pros and Cons, the chemical propulsion choices has four parts:

1. Choose the propellant type

$\square$ All cryogenic

Rationale: Required for high payload delivery throughput via higher natural $I_{s p}$ of hydrogen-oxygen combustion. High thrust first stage operation can be accomplished with highly efficient propellant fractions through investments in use Lox-rich (greater than 8: Imixture ratios) staged combustion cycles in advanced vehicle architectures.

口 Storable non-toxic

- Storable toxic

Solid hybrid solid fuel/self-pressurizing oxidizer

- Hybrid solid fuel pump fed oxidizer

\section{Choose specific propellant considering density and performance}

$\square$ Liquid hydrogen (normal boiling point)

Rationale: Keep propellant handling simple. Achieve advantageous propellant fraction characteristics (higher fuel load) via LOX rich operation - not via complex, burdensome, highly risky densification (colder than normal boiling point) ground and flight hardware.

ㅁ. Densified-hydrogen (triple point)

口 RP-1/kerosene

methane

propane

sub-cooled propane

- Shift mixture ratio to oxygen rich for sea-level and low altitude operation

Gelled propellants

$$
\text { 3. Choose a concept for cooling the rocket engine(s) }
$$

a Fuel cooled

$\square$ Oxygen cooled

$\square$ Hybrid cooling (combustion chamber cooled by oxygen, nozzle by fuel)

Rationale: [Need input from Russ Joyner]

Tridyne

4. Choose monopropellant or bi-propellant combination

C Cold Gas

- Hydrogen peroxide

口. Hydroxyl ammonium nitrate (HAN)

ㄱ Hydrazine

- Nitrous Oxide $\left(\mathrm{N}_{2} \mathrm{O}_{2}\right)$

प Hydrogen-oxygen, gas-gas

Rationale: Compatible with cryogenic main propulsion propellant supply system. Technology approach was successfully and dependably demonstrated during DC-X Program.

\section{D.Propulsion System Functional Integration}

Based on the Space Propulsion Choices-Pros and Cons, the propulsion system functional integration choices have four parts:

1. Select a rocket combustion cycle

$\square$ Staged combustion cycle driven by performance efficiency

Rationale: High performance engine cycle required for high throughput payload delivery.

Expander cycle driven by long life/dependability

G Gas generator cycle driven by simplicity and size flexibility

口 Tap-off cycle

व Pulse detonation combustion 
2. Choose a method for vehicle guidance and control steering

$\square$ Thrust Vector Control (TVC) by gimbaling rocket assembly with flexing propellant feed lines

Rationale: Selected due to choice of turbopump location/configuration

- Thrust Vector Control (TVC) by gimbaling rocket nozzles without flexing propellant lines

T TVC actuation by gimbaling - distributed hydraulic power

$\square$ TVC actuation by gimbaling - distributed electric power (electro-mechanical/electro-hydrostatic actuators, EMA/EHA)

Rationale: Avoid excessive flight and ground subsystem mass, complexity and dependability issues.

Jet and air vanes

․ Nozzle injection system

D Differential throttling of rocket nozzles

3. Choose a method for attitude control steering

■ TVC by gimbaling nozzles

Rationale: Most effective control method for example architecture

$\square$ Reaction Control with dedicated thrusters

Rationale: Most effective exo-atmospheric control method through use of $\mathrm{GH}_{2} / \mathrm{GO}_{2}$ (gas-gas) system supplied through main propellant tankage.

4. Choose a level of system hardware integration among on-board propulsion, power, and thermal management functions

\ Turbo-alternator driven from an autogenously pressurized tank system

\ Main propellant from common tanks feeding fuel cell power system

$\square$ In-Space control system (RCS) and main engines fed from common propellant tanks

$\checkmark$ In-Space orbital maneuvering propulsion system and/or RCS and/or main engines fed from common propellant tanks

$\square$ Active thermal management system fed from common propellant tank fluid

Rationale: Use of any or all of these approaches has the potential of overall design, development and support simplification - even if a few particular areas, such as distribution systems, require more design attention and conceptual mass margin

\section{E.Thermal Management Integration Approach}

Based on the Space Propulsion Choices - Pros and Cons, the thermal management integration choices have two parts:

1. Choose concept for tank-airframe structural integration

च Integral tank/structure

Rationale: Avoids added purge system complexity associated with alternatives.

W Wing tanks/aero-shell for vehicle lift

2. Choose concept for tank insulation approach

च Internal tank insulation for cryogenics thermal control and external insulation for re-entry heating structural control

Rationale: Consider to avoid ice/insulation shedding. Consider adding mass margin to accommodate if enables highly productive architecture.

a Complex purged composite insulation for total heat transfer control

Internal tank insulation for cryogenics thermal control and external insulations system that recovers useful heat energy for integrated functional use while providing protection from re-entry heating

Rationale: Consider for development to use available heat energy and avoid heated purges in reusable propulsion systems that would otherwise be required for time-consuming, burdensome propulsion system drying procedures, or heavy, voluminous on-board entry and descent nitrogen purge systems for same drying function. 
${ }^{1}$ Dehoff, B., Levack, D. J. H., and Rhodes, R. E., "The Functional Breakdown Structure (FBS) and Its Relationship to Life Cycle Cost," Technical paper AIAA 2009-5344, presented at 45th AIAA/ASME/SAE/ASEE Joint Propulsion Conference, Denver, Colorado, 2-5 August 2009.

${ }^{2}$ McCleskey, C. M., Rhodes, R. E., Chen, T. T., and Robinson, J. W., "High-Payoff Space Transportation Design Approach with a Technology Integration Strategy," Technical paper AIAA 2011-5571, presented at 47th AIAA/ASME/SAE/ASEE Joint Propulsion Conference \& Exhibit, San Diego, California, 31 July - 03 August 2011.

${ }^{3}$ Bollo, T., Garcia, J., McCleskey, C., from presentation "Affordability," presented to NASA Engineering Management Board (EMB), held at Kennedy Space Center, Florida, 5 June 2012.

${ }^{4}$ Verma, Dinesh, Dr., "System Architecture Representation," Stevens Institute of Technology, http://www.finse.org/2003Spring/presentations/Architecture\%20Representation\%20-\%20FINSE\%20Seminar.pdf, 2003.

${ }^{5}$ FreeDictionary.com: http://www.thefreedictionary.com/compatible [accessed 26 June 2012].

${ }^{6}$ Mankins, J. C., Highly Reusable Space Transportation: Advanced Concepts and the Opening of the Space Frontier, published in in Acta Astronautica, Vol. 51, No.10, Elsevier Sciences, Ltd., Great Britain, 2002; pp. 727-742.

${ }^{7}$ Commercial Space Transport Study (CSTS) Final Report, NASA web site:

http://www.hq.nasa.gov/webaccess/CommSpaceTrans/ [accessed June 2012], by the Commercial Space Transportation Study Alliance, May, 1994

${ }^{8}$ Smitherman, D. V., Jr., compiled by, NASA CP/1998-209006, New Space Industries for the Next Millennium, Marshall Space Flight Center, Huntsville, Alabama, December, 1998.

${ }^{9}$ Siceloff, S., "Reuse, Reliability Will Launch Future, Study Says," Kennedy News website:

http://www.nasa.gov/centers/kennedy/news/beyondnextgen.html NASA John F. Kennedy Space Center, 09.02.11.

${ }^{10}$ Bollo, T., et al.

${ }^{11}$ Organization of Economic Cooperation and Development; The Space Economy at a Glance-2011, http://www.oecd.org/dataoecd/63/5/48301203.pdf, accessed June 27, 2012.

${ }^{12}$ Drake, B. G., ed., Human Exploration of Mars: Design Reference Architecture 5.0, Mars Architecture Steering Group, NASA SP-2009-566, NASA Headquarters, Washington, D.C., July 2009.

${ }^{13}$ Isakowitz, S. J., et al., International Reference Guide to Space Launch Systems, $4^{\text {th }}$ ed., American Institute of Aeronautics and Astronautics, 1801 Alexander Bell Drive, Suite 500, Reston VA, 20191-4344, p. 113, 2004.

${ }^{14}$ Space-X website: http://www.spacex.com/falcon9.php, cited March 27, 2012.

${ }^{15}$ Isakowitz, S. J., et al.

${ }^{16}$ Legler, R. D., and Bennett, F. V., "Space Shuttle Missions Summary-Book 2; Next 100 Flights (STS97 through STS-115)", Rev. T, NASA Johnson Space Center, Houston, TX, February 2007.

${ }^{17}$ Kyle, Ed, "Launch Vehicle Reliability Statistics," Space Launch Report [online database], URL: http://www.spacelaunchreport.com/reliability2009.txt [cited June 2012].

${ }^{18}$ Isakowitz, S. J., et al., International Reference Guide to Space Launch Systems, $4^{\text {th }}$ ed., American Institute of Aeronautics and Astronautics, 1801 Alexander Bell Drive, Suite 500, Reston VA, 20191-4344, 2004.

${ }^{19}$ The Lompoc Record, article "Falcon Heavy set for VAFB launch," web citation:

http://www.lompocrecord.com/news/local/military/vandenberg/article b15a365e-6018-11e0-8da4-001cc4c03286.html, accessed June 27, 2012; article published 4 April 2011.

${ }^{20}$ Bergin, C., "NASA Exploration Roadmap: A return to the Moon's surface documented,"

http://www.nasaspaceflight.com/2012/03/nasa-exploration-roadmap-return-moons-surface-documented/, 19 March 2012.

${ }^{21}$ Bergin, C., "SLS Launch Vehicle specifications take shape as development continues," http://www.nasaspaceflight.com/2012/03/sls-specifications-take-shape-development-continues/, 16 March 2012.

${ }^{22}$ Rhodes, R. E., Zapata. E., Levack, D. J. H., Robinson, J. W., and Donahue, B. B., "Concepts for Life Cycle Cost Control Required to Achieve Space Transportation Affordability and Sustainability," Technical paper AIAA 2009-5345, presented at 45th AIAA/ASME/SAE/ASEE Joint Propulsion Conference, Denver, Colorado, 2-5 August 2009.

${ }^{23}$ McCleskey, C. M., Space Shuttle Operations and Infrastructure: A Systems Analysis of Design Root Causes and Effects," NASA TP-2005-211519, April 2005.

${ }^{24}$ Zeis, J., Operationally Efficient Propulsion Systems Study Data Book, Vol. VII-Launch Operations Index (LOI) Design Features and Options, RI/RD90-149- 7, NASA Kennedy Space Center 30 October, 1992.

25 National Aeronautics and Space Administration (NASA) Fiscal Year 2009 Budget Estimates, NASA web site: http://www.nasa.gov/pdf/210019main_NASA_FY09_Budget_Estimates.pdf, page Spa-12.

${ }^{26}$ Anonymous, "Shuttle Operations Zero-Base Cost Study," presentation to Dr. Lenoir, NASA Headquarters, Office of Space Flight, Washington, D.C., July 2, 1991.

${ }^{27}$ McCleskey, C. M., Space Shuttle Operations and Infrastructure: A Systems Analysis of Design Root Causes and Effects," NASA TP-2005-211519, April 2005. 
${ }^{28}$ Dehoff, B., Levack, D. J. H., and Rhodes, R. E., "The Functional Breakdown Structure (FBS) and Its Relationship to Life Cycle Cost," Technical paper AIAA 2009-5344, presented at 45th AIAA/ASME/SAE/ASEE Joint Propulsion Conference, Denver, Colorado, 2-5 August 2009.

${ }^{29}$ Bollo, T., Garcia, J., and McCleskey, C., "Spaceport business concept diagram," prepared for KSC Master Planning Working Group, April, 2012.

${ }^{30}$ McCleskey, C. M., Rhodes, R. E., Chen, T. T., and Robinson, J. W., "High-Payoff Space Transportation Design Approach with a Technology Integration Strategy," Technical paper AIAA 2011-5571, presented at 47th AIAA/ASME/SAE/ASEE Joint Propulsion Conference \& Exhibit, San Diego, California, 31 July - 03 August 2011.

${ }^{31}$ Wong, G. S., Zeis, J. M., Farhangi, S., Operationally Efficient Propulsion Systems Study Data Book, Vol. IV-OEPSS Design Concepts, RI/RD90-149-4, NASA Kennedy Space Center April 24, 1990.

${ }^{32}$ Armstrong, E. S., and Schlumberger, J. A., AIAA-90-2120, "Cooling of Rocket Thrust Chambers with Liquid Oxygen," $26^{\text {th }}$ Joint Propulsion Conference, Orlando, Florida, 16-18 July, 1990.

33 Joyner, C. R., II , Levack, D. J. H., and Rhodes, R. E., Robinson, J. W., "Propulsion System Choices and Their Implications," Technical paper presented at 46th AIAA/ASME/SAE/ASEE Joint Propulsion Conference, Nashville, Tennessee, July 25-28, 2010.

${ }^{34}$ Ibid.

${ }^{35}$ Wong, et al.

${ }^{36}$ Garcia, J, et al, "A Systems Approach to Developing an Affordable Space Ground Transportation Architecture using a Commonality Approach," $48^{\text {th }}$ Joint Propulsion Conference; Atlanta, Georgia, August 1, 2012.

${ }^{37}$ Fester, D. A., Robinson, J. W., and Bicknell, B. A., AIAA-86-1487 paper “A Compact, High-Performance Cryogenic Stage," $22^{\text {nd }}$ Joint Propulsion Conference, Huntsville, Alabama, 16-18 June 1986.

${ }^{38}$ Harmon, T. J., Operationally Efficient Propulsion Systems Study Data Book, Vol. VI-Space Transfer Propulsion Operational Efficiency Study task of OEPSS, RI/RD90-149-6, NASA Kennedy Space Center 30 October 1992.

${ }^{39}$ Bollo, T., Garcia, J., McCleskey, C., and Rhodes, R., from abstract in New Technology Report (NTR) Case no. KSC-13714, "Affordability Comparison Tool (ACT)," description, p. 1, submitted, 15 May 2012.

${ }^{40}$ ICD-2-0A002, Space Shuttle Launch Pad \& Platform, NASA Johnson Space Center, Houston, Texas

${ }^{41}$ Garcia, J, et al, "A Systems Approach to Developing an Affordable Space Ground Transportation Architecture using a Commonality Approach," $48^{\text {th }}$ Joint Propulsion Conference; Atlanta, Georgia, August 1, 2012. 


\title{
Approach to an Affordable and Productive Space Transportation System
}

\author{
Presented by \\ Carey M. McCleskey, NASA KSC \\ Senior Member, AIAA \\ Space Propulsion Synergy Team (SPST) Co-authors: \\ Edward M. Henderson (ret.) \\ Roger A. Lepsch, NASA LaRC \\ Russel E. Rhodes (ret.) \\ John W. Robinson
}

$48^{\text {th }}$ Joint Propulsion Conference, Atlanta, Georgia

August 1, 2012 
- Structured conceptual design approach to derive flight and ground architectures focused on affordable, productive, and sustainable space transportation

- Process to derive Earth-to-orbit flight architectures

- Commonality approach to derive a spaceport ground architecture

- Key Concepts:

- Affordability \& Sustainability

- Productiveness and Productivity

- Market / Design Reference Market

- Mission / Design Reference Mission (DRM) 


\section{The Approach}

1. Understand the space markets and define viable space business needs

2. Identify affordability and productivity improvement goals / objectives

3. Formulate design criteria and understand functions across the life cycle

4. Identify building block solutions (the how's)

5. Size vehicle /ground system concept compatible with objectives

6. Estimate improvement in architectural life cycle characteristics

The product will be an affordable and productive space transportation system

If you are affordable and not productive, or not affordability and productive, or even worse, not affordable and not productive... you will be cancelled or bankrupt 


\section{Step 1}

\section{Understand the space markets and define viable}

\section{space business needs}
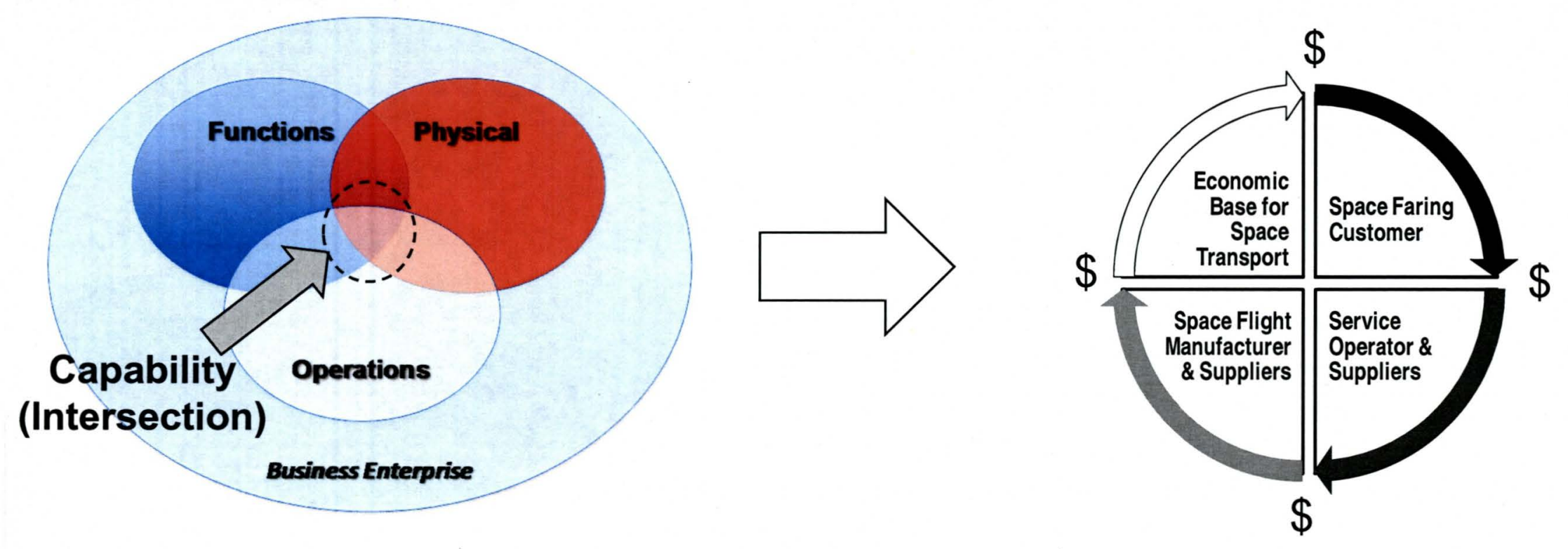

Mission-Driven Approach

- Flight performance drives architecture

- Affordability focus on development cost

- Operations characterized by execution of one-off missions

- Vehicle selection criteria based on payload capability-per-flight and costper-flight 


\section{Understand the space markets and define viable}

\section{space business needs}
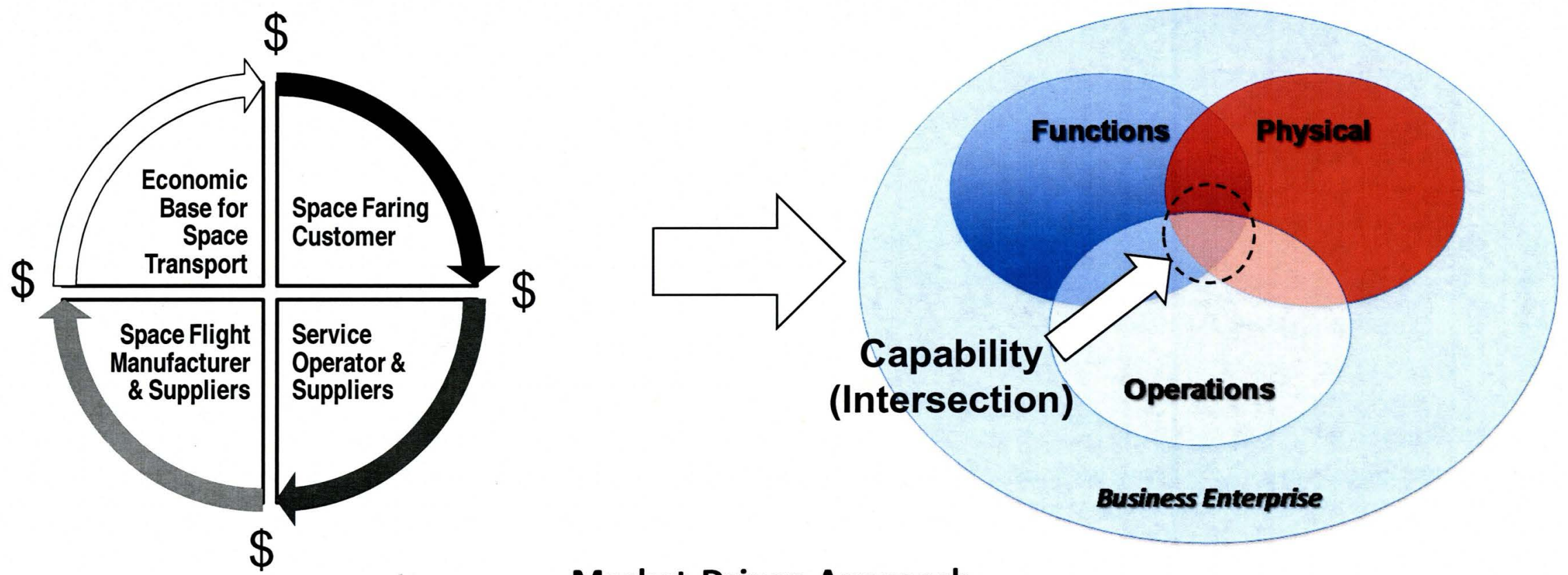

Market-Driven Approach

- Launch demand drives architecture

- Affordability focus on recurring cost

- Operations characterized by routine flights

- Vehicle selection criteria based on payload throughput per year and total recurring production and ops cost 


\section{Step 1}

\section{Understand the space markets and define} viable space business needs

Example NEEDS OF FUTURE MARKETS/MISSIONS (see Figure 5 in paper):

- [N-1] Frequent and high volume cargo deliveries

- [N-2] Frequent and high volume passenger deliveries

- [N-3] Safe, comfortable launch and landing experience, and unburdened ground experience for the passengers

- [N-4] Dependable arrivals and departures at the space enterprise locations

- [N-5] Ability to conduct routine assembly, servicing, and repair activities at a variety of destination locations (possesses large-scale in-space element and component handling devices)

- [N-6] Ability to conduct space rescue missions anytime, anywhere in low earth orbit

- [N-7] A means of routine, affordable transportation from one Earth orbit to another Earth orbit

- [N-8] Ability to house embedded airlocks for personnel transfer without time and effort involved for entire crew cabin to be evacuated and all personnel in cabin to don and doff pressure suits

- [N-9] Clean, effluent-free environment around arriving spacecraft 


\section{Identify Affordability / Productivity Goals \& Objectives}

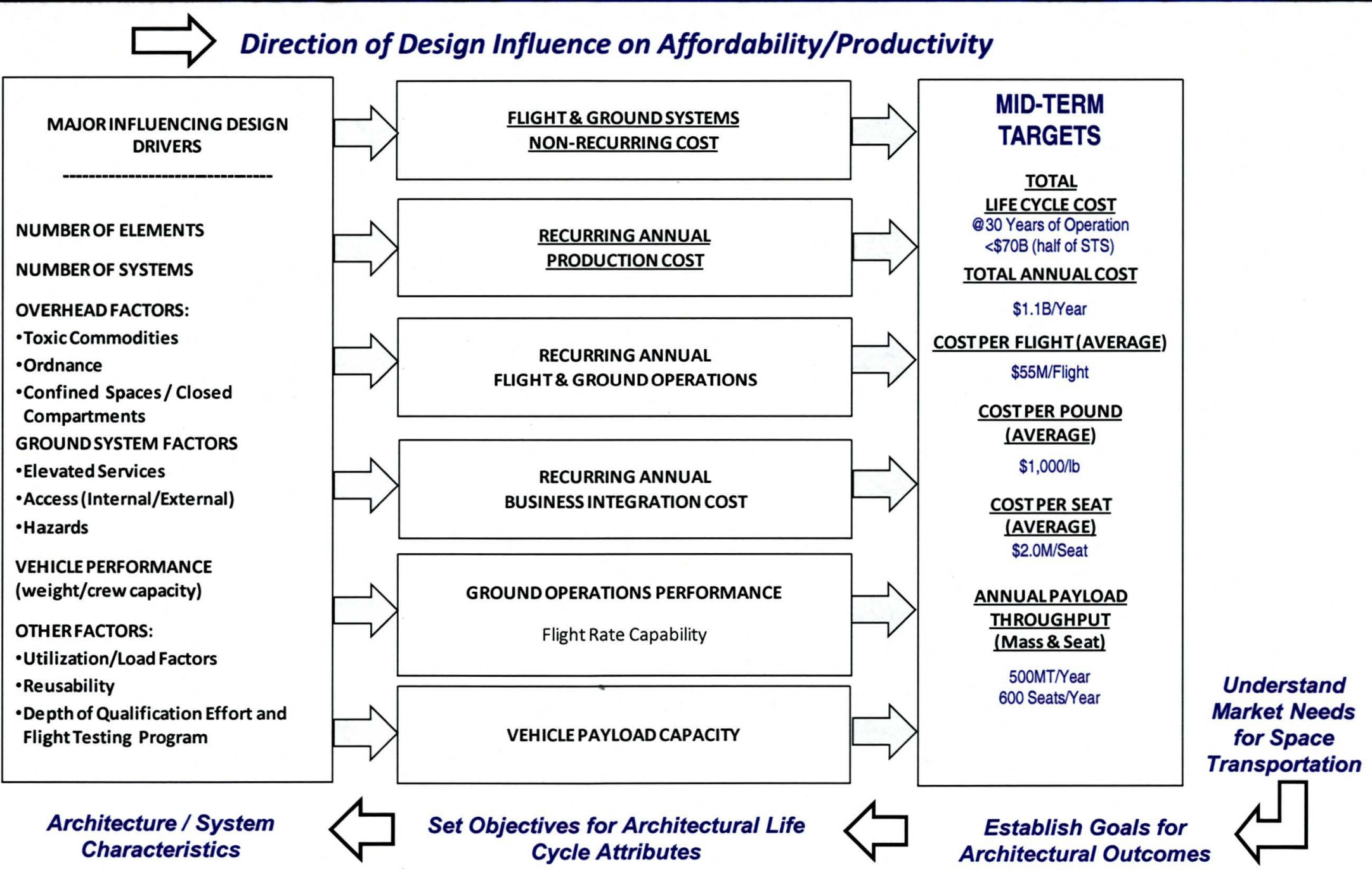

Direction of Requirements Flow to Create an Affordable/Productive Design

Forty-Eighth Joint Propulsion Conference, Atlanta, Georgia-August 1, 2012 


\section{Formulate design criteria and understand functions across the life cycle}

\section{Design Criteria that Address Design Drivers}

1. Total number of separate identified vehicle propulsion systems and/or separate stages

2. Total number of flight tanks in the architecture

3. Number of safety driven functional requirements to maintain safe control of systems during flight and ground operations

4. Number of maintenance actions unplanned before or between missions

5. Number of maintenance actions planned before or between missions

6. Total number of traditional ground interface functions required

7. Percent of all systems not automated

8. Number of different fluids required

9. Total number of vehicle element-to-element support systems

10. Number of flight vehicle servicing interfaces

11. Number of confined/closed compartments

12. Number of commodities used that require medical support operations and routine training

13. Number of safety driven limited access control operations

14. Number of safing operations at landing (for reusable elements)

15. Number of mechanical element mating operations

16. Number of separate electrical supply interfaces

17. Number of intrusive data gathering devices

18. Number of Criticality 1 system and failure analysis modes

\section{Ideal Functional-System} Breakdown Structure

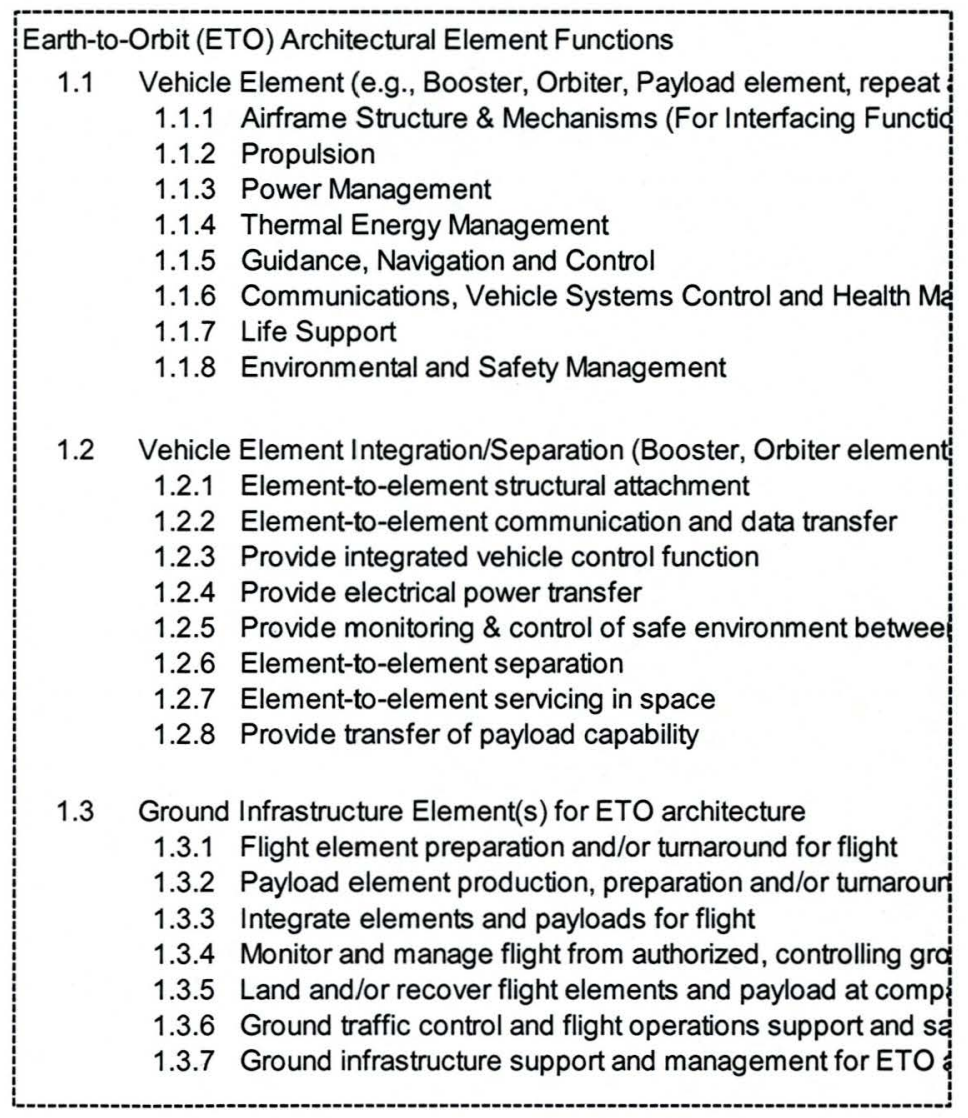

Attachment B of Paper 


\section{NASA}

\section{Step 4}

\section{Identify building block solutions (the how's) that improve architectural affordability \& productivity}

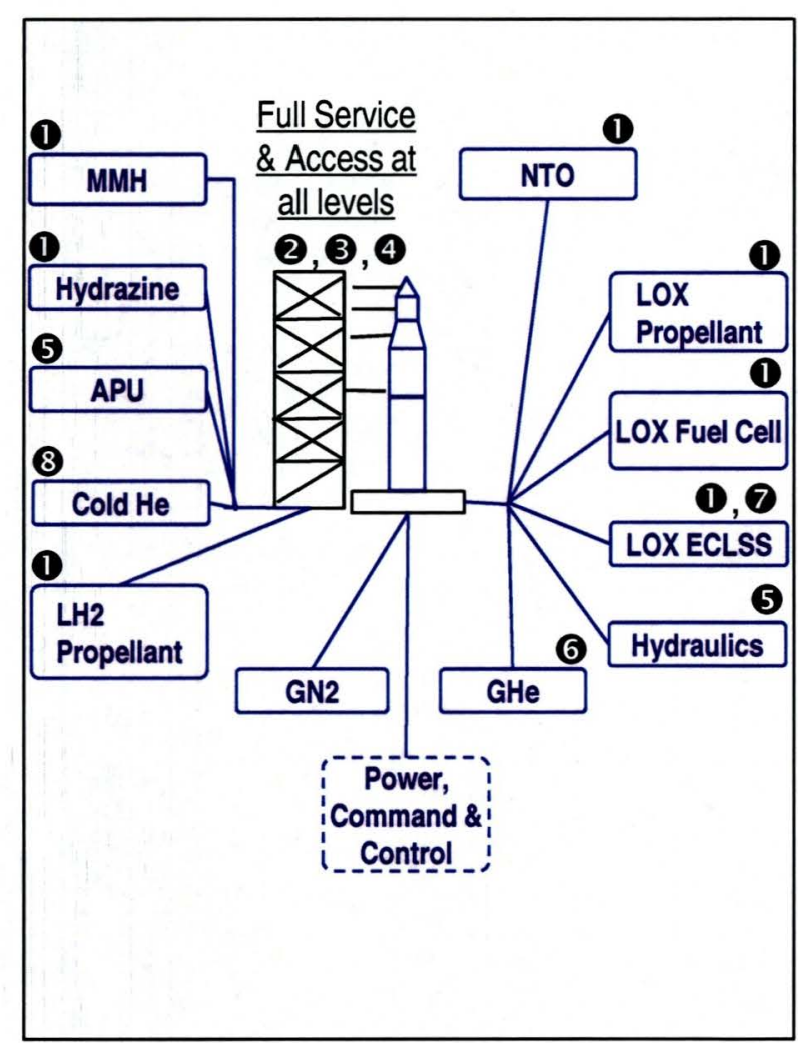

Less Affordable \& Productive
Example Techniques for Improving for Architectural Affordability

1. Minimize different propellant and avoid toxic

2. Minimize closed compartments

3. Maximize services provided from vehicle zero-level

4. Minimize long propellant feed lines through tank arrangements

5. Maximize use of electric powered actuators

6. Minimize pneumatic systems and conditioning

7. Maximize shared commodity storage

8. Minimize thermal conditioning

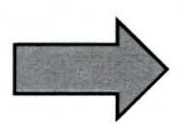

(More techniques are in the paper)

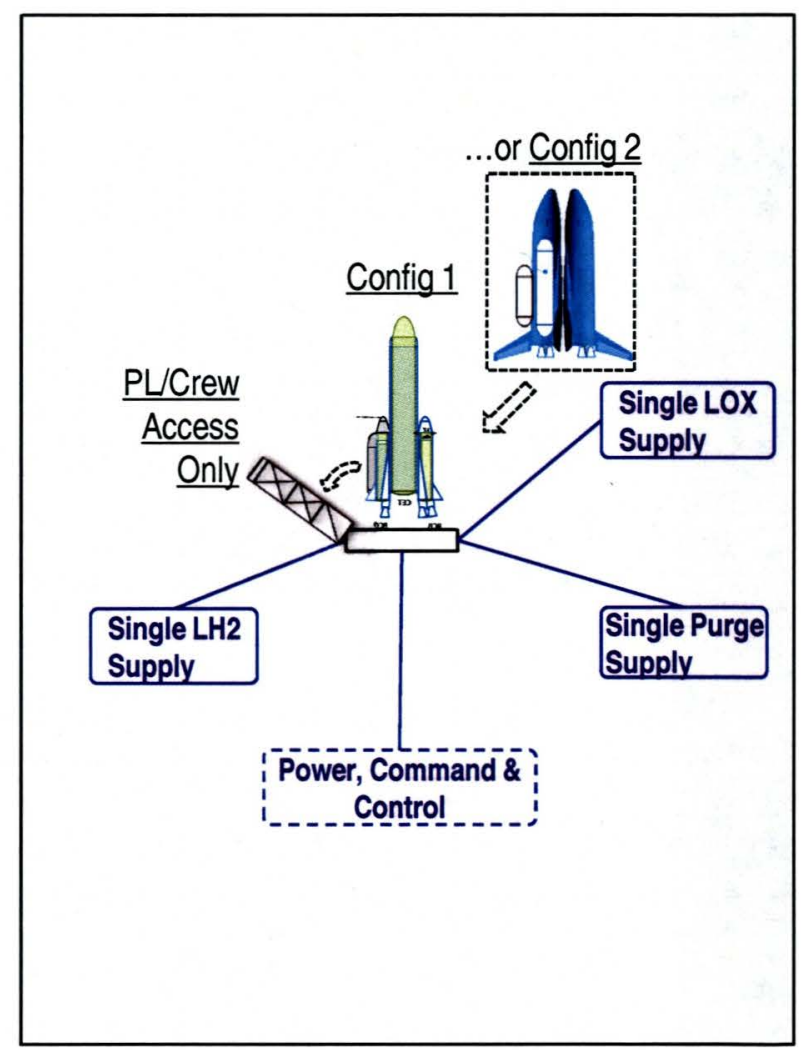

More Affordable \& Productive 


\section{Step 5}

\section{Design vehicle}

- Design vehicle system concept compatible with objectives (Step 2) and building blocks (Step 4)

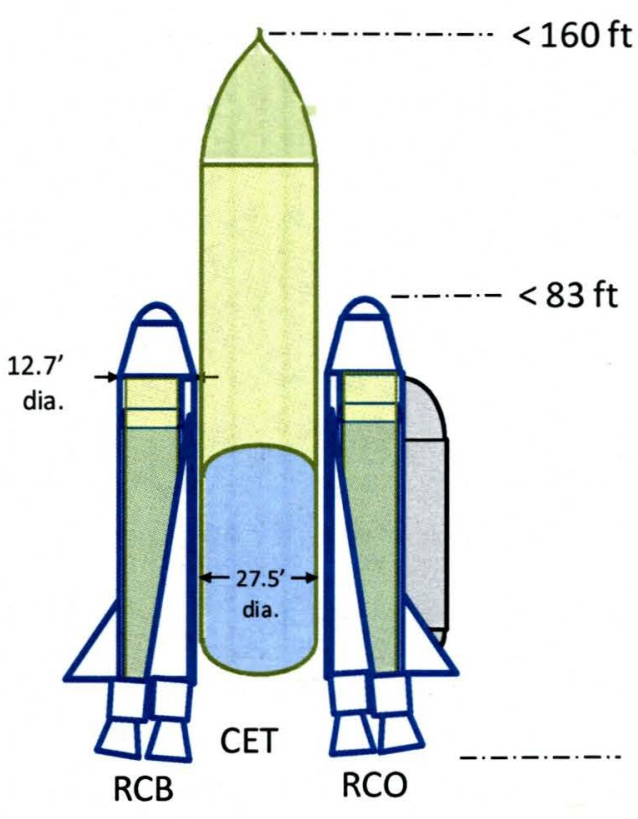

Notional Configuration 1

Central External Tank

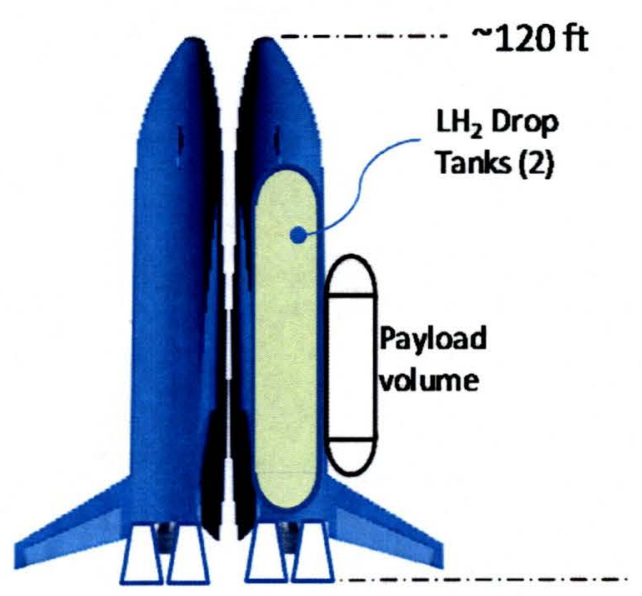

RCB RCO

Notional Configuration 2 Bimese with $\mathrm{LH}_{2}$ Drop Tanks

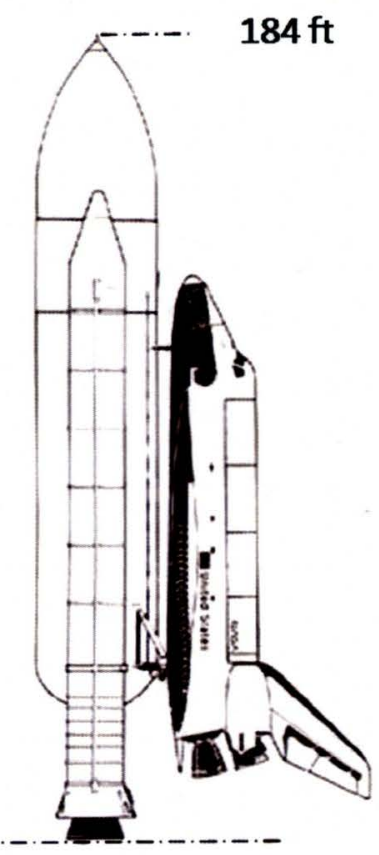

Space Shuttle (for comparison) 


\section{Step 6}

\section{Estimate improvement in architectural life cycle characteristics}

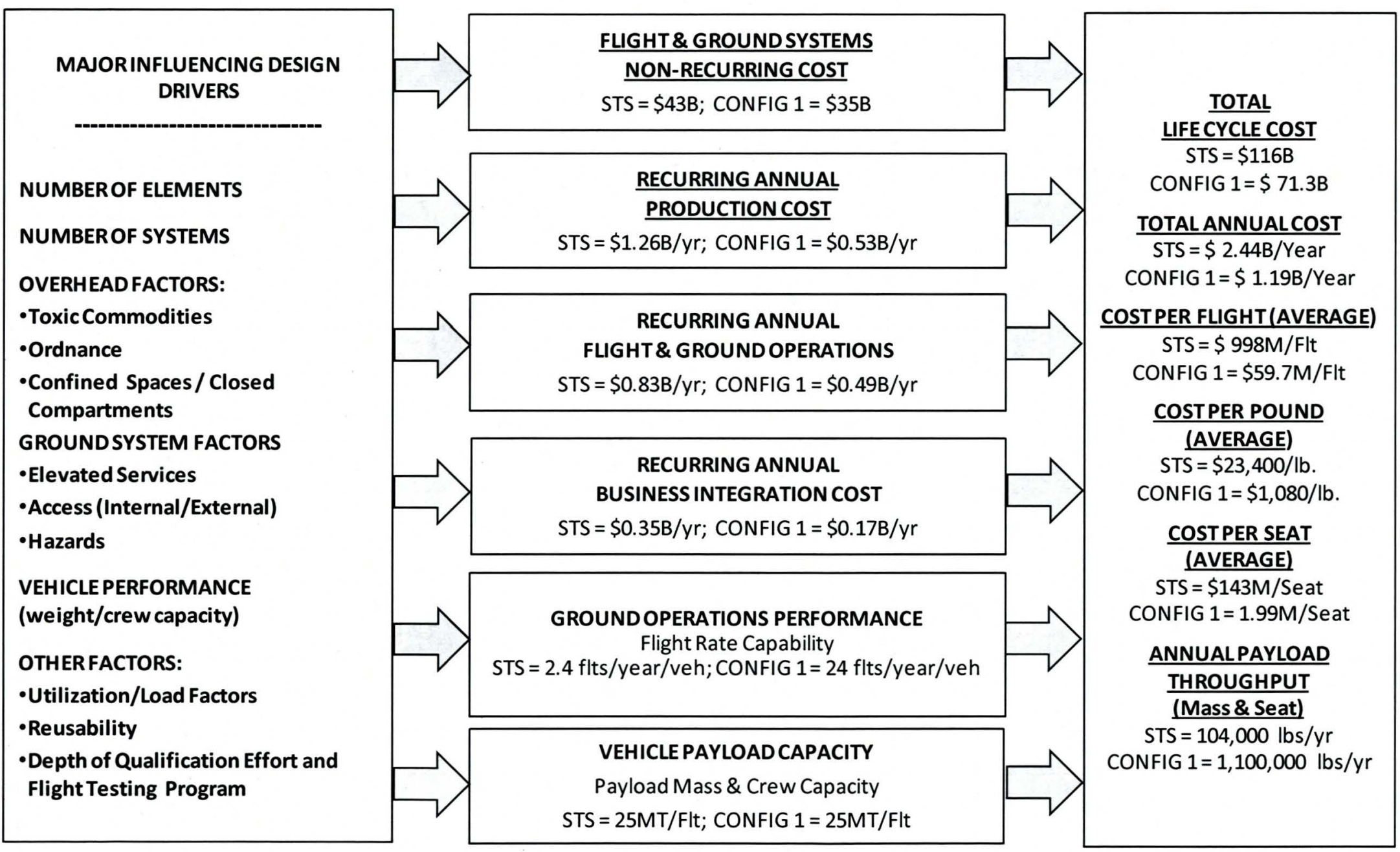

